\title{
On the Pricing of Step-Up Bonds in the European Telecom Sector
}

\author{
Lando, David; Mortensen, Allan
}

Document Version

Final published version

Publication date:

2004

\section{License \\ CC BY-NC-ND}

Citation for published version (APA):

Lando, D., \& Mortensen, A. (2004). On the Pricing of Step-Up Bonds in the European Telecom Sector.

Copenhagen Business School [wp].

Link to publication in CBS Research Portal

\section{General rights}

Copyright and moral rights for the publications made accessible in the public portal are retained by the authors and/or other copyright owners and it is a condition of accessing publications that users recognise and abide by the legal requirements associated with these rights.

\section{Take down policy}

If you believe that this document breaches copyright please contact us (research.lib@cbs.dk) providing details, and we will remove access to the work immediately and investigate your claim. 
WP 2004-9

On the Pricing of Step-Up Bonds in the European Telecom Sector

by

David Lando and Allan Mortensen

\footnotetext{
INSTITUT FOR FINANSIERING, Handelshøjskolen i København Solbjerg Plads 3, 2000 Frederiksberg C tlf.: 38153615 fax: 38153600

DEPARTMENT OF FINANCE, Copenhagen Business School Solbjerg Plads 3, DK - 2000 Frederiksberg C, Denmark Phone (+45)38153615, Fax (+45)38153600 www.cbs.dk/departments/finance
} 


\title{
On the Pricing of Step-Up Bonds in the European Telecom Sector*
}

\author{
David Lando ${ }^{\dagger} \quad$ Allan Mortensen ${ }^{\ddagger}$
}

November 12, 2004

\begin{abstract}
This paper investigates the pricing of step-up bonds, i.e. corporate bonds with provisions stating that the coupon payments increase as the credit rating level of the issuer declines. To assess the risk-neutral rating transition probabilities necessary to price these bonds, we introduce a new calibration method within the reduced-form rating-based model of Jarrow, Lando, and Turnbull (1997). We also treat split ratings and adjust for rating outlook. Step-up bonds have been issued in large amounts in the European telecom sector, and we find that, through most of the sample, step-up bonds issued by the two largest issuers have traded at a discount relative to comparable fixed-coupon bonds from the same issuers. Our findings cannot be attributed to traditional liquidity factors, and they suggest that issuing step-up bonds increased the cost of capital for the issuers.
\end{abstract}

Keywords: defaultable bonds, step-up coupons, rating-based models JEL classification: G12, G13

${ }^{*}$ We are extremely grateful to Søren Kyhl for many helpful discussions on the workings of the telecom bond market. We are grateful for helpful comments from Nicole Branger, Carl Chiarella, Darrell Duffie, Brian Huge, Gustavo Manso, P.C. Venkatesh, and from seminar participants at Moody's Investors Service (New York), Copenhagen Business School, Erasmus University, the 2004 FMA Annual and European meetings, the 2004 EFMA meetings, and Ph.D. workshops at the Danish Doctoral School of Finance and New York University. Finally, we are grateful to Roger Stein and Moody's/KMV for providing us with EDF data, and to Michael Bødker for providing us with bond data. All errors are of course our own.

${ }^{\dagger}$ Professor, Department of Finance, Copenhagen Business School, Solbjerg Plads 3, DK-2000 Frederiksberg, Denmark, (+45) 3815 3613, dl.fi@cbs.dk

$\ddagger$ Ph.D. candidate, Department of Finance, Copenhagen Business School, Solbjerg Plads 3, DK-2000 Frederiksberg, Denmark, (+45) 3815 3629, am.fi@cbs.dk 


\section{Introduction}

The corporate bond market in the European telecommunication sector has in recent years seen a dramatic increase in the number and volume of corporate bond issues with embedded step-up covenants, i.e. provisions which link the cash flow of the bond to the credit rating of the issuer by increasing the coupons as the rating declines. In this paper, we study the pricing of step-up bonds relative to comparable fixed-coupon bonds issued by the two largest issuers, Deutsche Telekom and France Telecom. We find evidence that the step-up bonds have traded at a discount relative to fixed-coupon debt through most of the sample. This evidence is consistent with the idea that 'complicated' securities may have excess expected returns, possibly because of limited participation or higher parameter uncertainty in the relevant pricing models. Such an explanation is supported by the observation that the discount on the step-up bonds tends to disappear as they approach maturity, and the uncertainty on the cash flow, due to the step-up feature, therefore vanishes.

The idea of linking credit quality to cash flows is not new. Step-up bonds are a special case of credit-sensitive notes, which were first issued in the late 1980s, and similar principles underlie credit-linked notes and credit triggers in swaps. What is remarkable in the case of European telecom step-up bonds, however, is the large volume of issuance - making the secondary market for these bonds highly liquid. Despite the large liquidity of the bonds, a feeling among many market participants, that we have talked to, is that the step-up bonds in the telecom sector are often mispriced and typically underpriced. ${ }^{1}$ Our results confirm this observation, and we argue that the pricing differences cannot be attributed to traditional liquidity factors. This is again consistent with the fact that bonds which lose their step-up feature trade at prices similar to those with no step-up provision. The conclusion is robust to a number of alternative specifications. This robustness derives from the fact that our approach is a relative pricing exercise. For example, the specification of recovery rates or of riskless interest rates affects the two types of bond in approximately the same way, and therefore the relative pricing is largely unaffected.

The underpricing of step-up bonds in the secondary market is interesting since this type of bond has come to comprise a sizable part of the European corporate bond market. Furthermore, our findings suggest that issuing step-up bonds increased the cost of capital for the issuers, which is important since step-

\footnotetext{
${ }^{1}$ Two examples from investment bank notes include: "The market does not appear to be assigning specific value to the credit protection in each bond. It is our view that the credit protection features have value, and that these issues are trading cheap to their market levels when taking this into account" Lehman Brothers, Credit-sensitive Telecom Bonds (July 13, 2000), and "... we continue to think the market is, in fact, undervaluing these [step-up] options prior to imminent ratings actions ... they are essentially being offered for free in various outstanding securities" Deutsche Bank, European Credit Strategy (January 19, 2001).
} 
up bonds account for almost a quarter of total liabilities, at the end of 2002, for the two companies we consider.

This raises the question of the rationale behind the issuance of corporate bonds with step-up provisions. In practise, the provisions can be viewed as a partial hedge against losses arising from downgrades. Investors may fear that the market will react strongly to downgrades, possibly because fund managers will have to abandon positions as the rating approaches speculative grade. From a theoretical point of view, step-up bonds may reduce the agency costs of debt identified by Jensen and Meckling (1976). The step-up provisions can be seen as a means for the management of the issuing company to signal that it will and can comply with the target leverage ratios required by the rating agencies to retain ratings above the step-up trigger level. From the perspective of bankruptcy costs and tax benefits from debt, however, step-up bonds seem inefficient. Step-up bonds have lower tax benefits since the tax shields (the coupons) are high when profits are low, and as argued by Manso, Strulovici, and Tchistyi (2003) they have higher bankruptcy costs than equivalent fixed-coupon bonds due to what is sometimes referred to as the credit-cliff. The problem is that the liabilities of the debtor increase when the credit quality of the debtor is already decreasing, which tends to increase the probability of default. A potential credit-cliff does not affect our conclusions, since we study the pricing of step-up bonds relative to fixed-coupon bonds of the same debtor, which should also reflect a potentially increased default probability.

A natural framework for the pricing of rating-sensitive securities is the reducedform rating-based model introduced by Jarrow, Lando, and Turnbull (1997, JLT) and Lando (1994), and carried forward for example in the works of Das and Tufano (1996), Kijima and Komoribayashi (1998, KK), Lando (1998) and Arvanitis, Gregory, and Laurent (1999). We implement the precise (and often complicated) structure of the step-up provisions in the model of JLT, allowing for split ratings and rating outlooks. In assessing the risk-neutral rating transition probabilities, we propose a new calibration method which overcomes the numerical problems with the method of JLT and is economically intuitive as opposed to the method of KK. We illustrate that the choice of calibration method is critical for the nondefault entries of the implied rating transition matrix and therefore potentially important for the pricing of rating-sensitive assets.

The pricing of credit-sensitive notes was first studied by Ogden and Moon (1993) without modelling the rating transitions. Das and Tufano (1996) priced creditsensitive notes in a model extending the setup of JLT to stochastic recovery rates. They relied on the method of JLT in obtaining the risk-neutral rating probabilities which is, as we shall see, not robust to large deviations between empirical and implied default probabilities. Acharya, Das, and Sundaram (2002) also priced credit-sensitive notes, also applying the JLT calibration method, but they did not consider the market valuation of step-up bonds.

The pricing of step-up bonds in the JLT model has also been analyzed in a 
parallel study by Houweling, Mentink, and Vorst (2004b). This paper differs in several respects. Firstly, the focus of that paper is a comparison of three different step-up valuation models, whereas our focus is to what extent step-up bonds have been priced at a discount relative to fixed-coupon bonds. Secondly, they apply the calibration method of KK, and they do not implement the full details of the stepup provisions. We propose a more intuitive calibration method, and we address the complications of split ratings and rating outlook. Thirdly, we study a larger group of bonds and a much longer sample period, including the more interesting period where step-up triggers have been activated. The value of step-up clauses has also been estimated in a few investment banks notes. The ones we are aware of, however, apply either subjective or historical rating transition probabilities and do not give quantitative statements regarding the market valuation of step-up bonds through time.

In an empirical study on European telecom corporate bonds, Newman and Rierson (2003) find downward-sloping demand curves, i.e. credit spreads are positively related to aggregate industry-wide debt issuance. This applies to all issues of the companies and thus does not affect our relative pricing analysis.

The outline of the paper is as follows. In Section 2 we describe the market for step-up bonds and the precise language of the provisions. Furthermore, we present our data and make the first crude assessment of the market values attached to the provisions. Section 3 presents the rating-based model in which we will be working. Section 4 discusses real-world and risk-neutral rating transition probabilities. Section 5 reports results of calibrating the rating-based model to fixed-coupon bonds to compare theoretical and market values of step-up bonds. Section 6 concludes.

\section{Provisions and their market values}

Corporate bonds with step-up provisions have primarily been issued by the major companies in the European telecom sector, most of which are former state monopolies. These companies have been forced by liberalization of the market into more high risk/high yield activities, most notably in the mobile phone market. In particular, the major players needed to finance their participation in auctions for the so-called UMTS licenses needed to operate the 'third-generation' mobile phone technology. The huge expenses to acquire these licenses (the auctions produced a total revenue of 120 billion euros in Europe), the large expenses in actually developing the new technology (estimates are as high as 80 billion euros in total) and the high uncertainty in estimating the cash flows produced by the new technology caused strong negative reactions in the equity markets. These negative reactions were reinforced by the general downturn in the technology sector and have made equity financing less attractive. Instead the major companies in the telecom sector have financed the investments through large debt issues, and most 
of these issues in recent years had step-up provisions. By February 2003, the market for step-up telecom bonds consisted of 65 issues with a total euro equivalent outstanding amount of 107 billion. ${ }^{2}$ In addition to that, a few step-up bonds have been issued in other sectors. Deutsche Telekom (DT), France Telecom (FT) and British Telecom are the three major issuers accounting for $30 \%, 23 \%$ and $17 \%$, respectively, of the total amount. The problems of the telecom sector and the increased leverages caused a line of downgrades from the rating agencies, which has activated many of the step-up clauses. The rating activity involving DT and FT is summarized in Table 7, Appendix A. In less than three years Moody's and Standard \& Poor's (S\&P) in total downgraded DT by 11 notches and FT by 14 notches. ${ }^{3}$ Despite the problems of the telecom sector, investors may be convinced that the companies offer a limited risk of actual default, simply because many of the companies still have a large fraction of shares owned by the government and because they are so vital in providing infrastructure that they are in a sense 'too big to fail'. ${ }^{2}$

The cash flow of the step-up bonds is explicitly linked to the credit rating of the issuer. The precise language of the link varies from issue to issue, but for all issues it is defined in terms of the ratings with modifiers of senior unsecured debt from the two major rating agencies, Moody's and S\&P.

Provisions have different step amounts and different rating event triggers. In some cases, as with the DT issues, a step-up of the coupon requires a downgrade to the trigger level by both rating agencies. In other cases, as with the FT issues maturing in 2004 and 2008, there are step-up triggers for actions of each rating agency. Here, a downgrade by one agency will trigger an increase in the coupon regardless of the rating from the other agency.

Provisions also vary with respect to step-down features which, as the name suggests, trigger a lowering of the coupon if the company regains its original rating after a downgrade. There is no step-down below the initial coupon for ratings exceeding the initial rating. ${ }^{5} \mathrm{KPN}$ and Telstra have issued step-up bonds

\footnotetext{
${ }^{2}$ Market statistics are from "Telecom Coupon Steps - Navigating the Maze and Disseminating Value", Credit Suisse First Boston (February 14, 2003).

${ }^{3}$ Notches refer to the rating system with modifiers. For example a movement from Baa1 to Baa2 in Moody's system is a one notch move.

${ }^{4}$ This is also explicitly recognized by the rating agencies, particularly evident in the case of FT. As we shall see, the rating of FT has for a long period been several categories better than the rating implied by the EDF (the Moody's/KMV measure of credit quality). The French government, holding $55.5 \%$ of the equity, has on several occasions indicated that it will support the debt-reduction programme of FT. In December 2002, the government granted FT a 9 billion euro loan, the terms of which are being investigated by the European Commission for illegal state aid.

${ }^{5}$ Credit-sensitive notes with step-down below the initial coupon have been observed, e.g. the Enron issue considered by Ogden and Moon (1993) and Das and Tufano (1996). Results indicated that this covenant had positive market value due to a large step-up schedule and only a small step-down schedule below the initial coupon.
} 
without step-down provisions making these issues path-dependent. However, the most common construction stipulates that coupons are stepped down if the rating rises above the trigger level again, which is also the case for the issues of DT and FT. If a step-up is triggered by a unanimous downgrade, as for the DT issues and one of the FT issues, it requires a unanimous upgrade by both agencies to step down the coupon again. This way of structuring step-down makes these issues path-dependent as we shall see in Section 3.1.

Additionally, the provisions differ with respect to what happens with further downgrades. The DT issues only have two possible coupon levels, whereas the FT and British Telecom issues have continual step-ups for every further downgrade.

Typically, the change of coupon takes place on the second coupon date after the triggering change of rating has been announced, i.e. the change of coupon starts accruing at the following coupon date. This is the case for the DT and FT step-up bonds. For a few issues of KPN and Telstra, however, the change of coupon is effective immediately and calculated as a pro-rata step-up for the remaining part of the coupon period. This structure is computationally more involved since rating probabilities are needed at any point in the future and not just at discrete coupon dates, as in the cases we consider.

\subsection{Data}

Our relative pricing approach requires fixed-coupon bonds of the same issuers comparable to the step-up issues in terms of currency, liquidity and priority. We refer to the comparable fixed-coupon bonds as reference bonds. We restrict our sample to issuers with at least two reference bonds, which leaves us with the euro issues of DT and FT. As mentioned DT and FT are the most active issuers of step-up bonds, accounting for more than half of the total market outstanding amount. For the third largest issuer, British Telecom, and for the dollar step-up issues of DT and FT, there are too few reference bonds. We exclude DT step-up bonds maturing after 2010 from our analysis since the longest DT reference bond matures in 2008. Table 1 lists the step-up bonds in our study, covering around $20 \%$ of the market for step-up bonds.

As reference bonds we select all fixed-coupon bonds satisfying the following criteria: non-callable, same priority as the step-up bonds, issued in euro, outstanding amount of at least 500 million euro, issued after January 1, 1998, and time to maturity more than six months. This leaves us with the reference bonds listed in Table 1. One fixed-coupon bond (DT 4.25\% maturing Jan 17 2005) is excluded since the price data indicate low liquidity - we observe 20 unchanged day-to-day prices for this bond. In the latter part of the sample we have up to five reference bonds from each issuer, whereas in the early part we only have two. This is not much to estimate the issuer-specific discount curves, but we leave out the illiquid bonds since, in particular, some of the smallest DT and oldest FT bonds are severely affected by low liquidity due to low circulating amounts. The 


\begin{tabular}{|c|c|c|c|c|c|}
\hline & $\begin{array}{l}\text { Amount } \\
\text { m EUR }\end{array}$ & Issued & $\begin{array}{l}\text { Rating level } \\
\text { to trigger }\end{array}$ & $\begin{array}{l}\text { Agency } \\
\text { to trigger }\end{array}$ & $\begin{array}{l}\text { Step-up } \\
\text { amount, bp }\end{array}$ \\
\hline \multicolumn{6}{|l|}{ Step-up bonds: } \\
\hline DT $6.125 \%$ Jul 62005 & 2,250 & Jun 2000 & $\mathrm{Baa1} / \mathrm{BBB}+$ & both & 50 one-off \\
\hline DT $5.875 \%$ Jul 112006 & 4,500 & Jul 2001 & $\mathrm{Baa1} / \mathrm{BBB}+$ & both & 50 one-off \\
\hline DT $7.5 \%$ May 292007 & 2,500 & May 2002 & $\mathrm{Baa} 2 / \mathrm{BBB}$ & both & 50 one-off \\
\hline DT $6.125 \%$ Dec 42007 & 500 & Nov 2002 & $\mathrm{Baa} 2 / \mathrm{BBB}$ & both & 50 one-off \\
\hline DT $5.75 \%$ Feb 122008 & 1,000 & Jan 2003 & $\mathrm{Baa} 2 / \mathrm{BBB}$ & both & 50 one-off \\
\hline DT $6.5 \%$ Oct 72009 & 500 & Sep 2002 & $\mathrm{Baa} 2 / \mathrm{BBB}$ & both & 50 one-off \\
\hline FT $5.75 \%$ Mar 142004 & 3,500 & Mar 2001 & Baa1/BBB+ & either & 25 per notch, per agency \\
\hline FT 5\% Feb 262005 & 2,750 & Nov 2001 & $\mathrm{Baa} 2 / \mathrm{BBB}$ & both & 20 per notch \\
\hline FT $6.75 \%$ Mar 142008 & 3,500 & Mar 2001 & Baa1/BBB+ & either & 25 per notch, per agency \\
\hline \multicolumn{6}{|l|}{ Reference bonds: } \\
\hline DT $4.625 \%$ Aug 282003 & 1,000 & Aug 2001 & & & \\
\hline DT $5.25 \%$ Sep 242004 & 500 & Sep 2002 & & & \\
\hline DT $5.5 \%$ Sep 302005 & 500 & Sep 2002 & & & \\
\hline DT $5.25 \%$ Jan 222007 & 500 & Jan 2002 & & & \\
\hline DT 5.25\% May 202008 & 2,000 & May 1998 & & & \\
\hline FT $6.125 \%$ Nov 102005 & 1,000 & Oct 2000 & & & \\
\hline FT $6 \%$ Sep 282007 & 1,000 & Jan 2003 & & & \\
\hline FT 7\% Dec 232009 & 2,000 & Dec 2002 & & & \\
\hline FT $6.625 \%$ Nov 102010 & 1,400 & Oct 2000 & & & \\
\hline FT $7.25 \%$ Jan 282013 & 3,000 & Jan 2003 & & & \\
\hline
\end{tabular}

Table 1: Euro step-up and reference bonds issued by DT and FT. Ratings are Moody's/S\&P. Reference bonds are comparable fixed-coupon bonds. All bonds have annual coupon payments. Source: Bloomberg and bond prospectuses.

low number of reference bonds does not allow us to derive a unique arbitrage-free step-up bond price, but we can still get estimates for the relative pricing of stepup bonds using different reference bonds and calibration methods. We return to this issue in Section 5.2.

Throughout this paper we use daily bond prices from Bloomberg, obtained from the Bloomberg generic price source. As the default-free benchmark, we take the German government zero-coupon yield curve obtained from Bundesbank, estimated by the extended Nelson-Siegel method of Svensson (1994). The sample period for DT is August 6, 2001, to October 7, 2003, the start of which is chosen as the issue date of the second DT reference bond. The sample period for FT is March 7, 2001, to October 7, 2003, beginning with the issuance of the first FT step-up bonds. The sample consists of 551 and 656 trading days for DT and FT, respectively. We observe 13 unchanged day-to-day bond prices (with 4 decimals). We interpret an unchanged price as a missing price for a bond that was not traded and remove them from the sample.

Several studies have documented liquidity effects in asset pricing, i.e. the fact 
that investors require a premium for holding assets with lower liquidity than otherwise identical assets. Amihud and Mendelson (1991) and Warga (1992) showed that liquidity risk is priced for U.S. government bonds. This has also been documented for European corporate bonds in a recent study by Houweling, Mentink, and Vorst (2004a) using a number of liquidity measures. Our dataset provides three indirect liquidity measures: size, age and missing prices. These three proxies were all found to carry significant liquidity premia in Houweling, Mentink, and Vorst (2004a). Sarig and Warga (1989) argue that liquidity increases with issue size and decreases with the age of an issue, since the circulation amount decreases. Furthermore, the number of unchanged day-to-day prices can be seen as a proxy for quote frequency.

By selection, the size and age are approximately the same in the two groups of bonds. On average, the step-up bonds have larger outstanding amounts than the fixed-coupon bonds, which are however also fairly large issues. The ages in the two groups are comparable. For DT, we observe 11 unchanged day-to-day market prices for the step-up bond maturing in 2005 and none for all the other bonds. Thus, this single step-up bond could be less liquid than the reference bonds but this is not the case for the rest of the step-up bonds. We keep this bond in the sample for completeness, and we will see that the results for this step-up bond do not differ from those of the other step-up bonds. For FT, we observe one missing price for each of the two groups of bonds. All in all, there is no evidence from traditional liquidity proxies that step-up bonds should, in general, be less liquid than the reference bonds.

\subsection{Market values}

In this preliminary analysis we estimate the market value attached to each of the step-up clauses (on each given trading day) by computing the difference between the observed market price of the step-up bond and the theoretical value of the same bond obtained by discounting the bond's regular cash flow on a firm-specific yield curve. The regular cash flow is the minimal cash flow, the bondholder will receive, if there is no default before maturity. Hence, the regular cash flow seen from date $t$ consists of the initially scheduled payments after $t$ and possibly an already triggered step-up payment at the first coupon date after $t$. Thus, a negative market value would be evidence of underpricing - a negative price for the non-negative potential future step-up payments above the initial coupon level. The issuer-specific yield curves are obtained by fitting the credit spreads above the German government zero-coupon yield curve for the reference bonds. In doing that, we apply a continuous piecewise-linear bootstrapping method requiring 
constant spreads outside the range of available maturities. ${ }^{6}$ Figure 1 presents the bootstrapped credit spreads. The spreads have generally had an increasing trend in the early part of the sample, consistent with the increasing leverage ratios, followed by a massive decline in 2003 .

Figure 2 illustrates the calculated market values in percentage of face value for selected step-up issues, whereas Table 2 summarizes the market values for all the step-up bonds in consideration. In general the provisions of FT have higher market value than the provisions of DT, which was to be expected since the DT provisions have a maximum step-up of only $50 \mathrm{bp}$. As can be seen, the market values fluctuate a lot and are not persistently positive. In fact, all DT step-up provisions have negative market values on average in the periods before step-up payments have been triggered. The provisions only have significant positive market values in periods where step-up triggers have been activated. The sub-samples suggest a general trend that the market values of step-up provisions have increased consistent with the declining credit ratings. Furthermore, if we extrapolate the constant credit spread to longer maturities, calculations not shown indicate that DT step-up provisions maturing in 2010, 2011 and 2012 also have had significantly negative market values.

One could argue that the reference bonds used to construct the company curves are too few. The conclusion for the step-up bonds, however, is general across all maturities. We observe periods with negative provision market values for all step-up bonds whether they mature before, between or after the reference bonds used to construct the firm-specific curves. In fitting the curves, we assume a linear spread structure between reference bonds. The structure between reference bonds could be concave but to explain all the negative step-up market values, the structure would need to be convex between step-up bonds. It seems very hard to come up with a reasonable story about firm-specific default probabilities that would lead to a credit spread structure with significant humps at all the step-up maturities. In particular towards the end of the sample, we see negative values for the latter step-up issues although we have more reference bonds to estimate the firm-specific spread curve. As mentioned, we will return to this important issue in Section 5.2.

Summing up, the first investigation suggests that in general the market values attached to the step-up provisions are very volatile and in fact very small - in

${ }^{6}$ To be clear, assuming we calibrate to $N$ bonds maturing at $T_{1}<\cdots<T_{N}$,

$$
\text { spread }_{t}= \begin{cases}\alpha_{1} & \text { for } t \leq T_{1} \\ \frac{T_{n+1}-t}{T_{n+1}-T_{n}} \alpha_{n}+\frac{t-T_{n}}{T_{n+1}-T_{n}} \alpha_{n+1} & \text { for } T_{n}<t \leq T_{n+1}, n=1, \ldots, N-1 \\ \alpha_{N} & \text { for } t>T_{N}\end{cases}
$$

where $\alpha_{1}, \ldots, \alpha_{N}$ are chosen to match the $N$ bond prices exactly. This appears to be more robust than a piecewise-constant bootstrapping method especially when the distances between maturities are relatively large. 

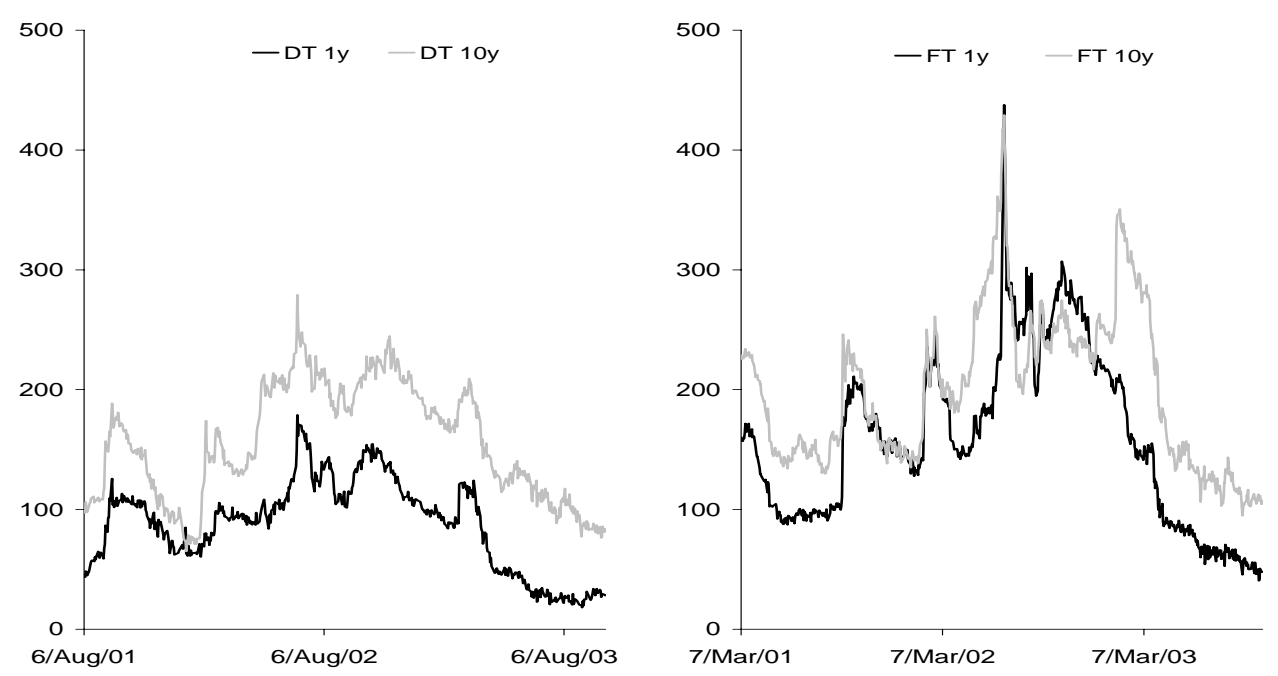

Figure 1: Yield spreads (bp) for maturities one and ten years. Obtained by bootstrapping the yield spread above the German government zero-coupon yield curve for the reference bonds.
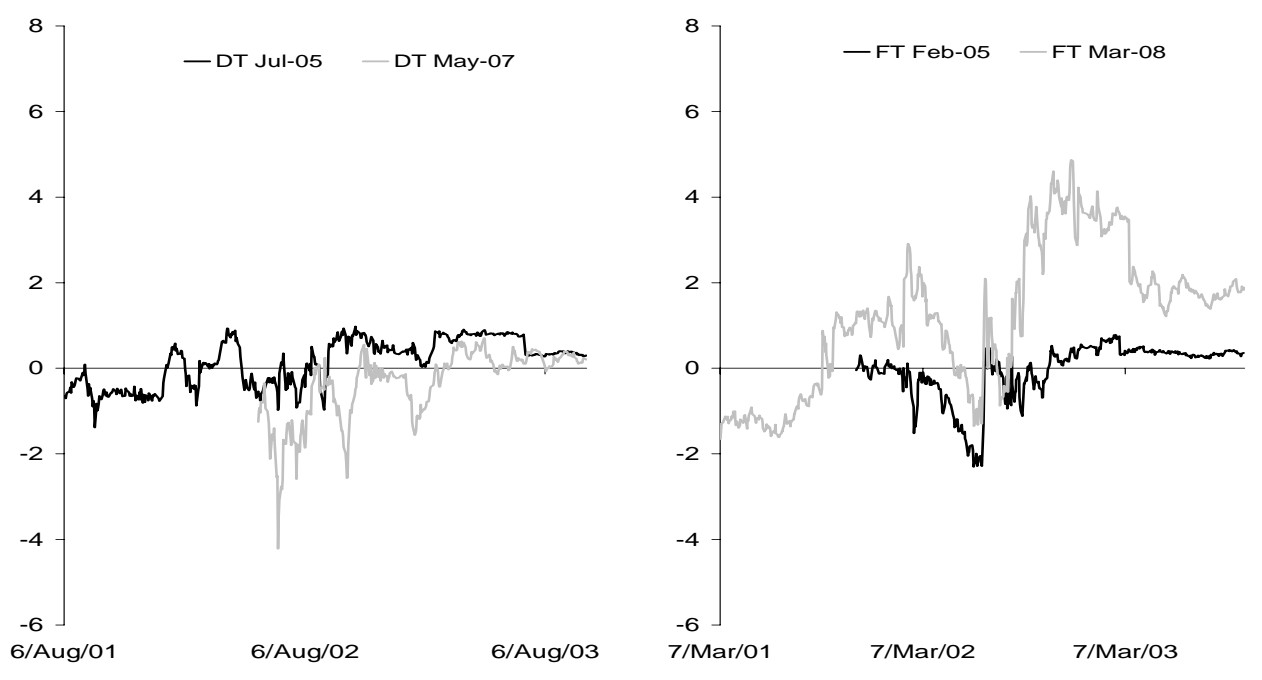

Figure 2: Estimated market values (in \% of face value) of step-up provisions. The market value is computed as the market price minus the theoretical value of the regular cash flow valued on a firm-specific zero-coupon yield curve. The regular cash flow is defined as the remaining part of the initially scheduled payments plus a potentially already triggered step-up payment at the next coupon date. 


\begin{tabular}{lcrrr}
\hline & Entire sample & Sub-sample & Sub-sample & Sub-sample \\
& & 2001 & 2002 & 2003 \\
\hline DT 6.125\% Jul 6 2005 & $0.15(0.54)$ & $-0.57(0.20)$ & $0.13(0.50)$ & $0.55(0.25)$ \\
DT 5.875\% Jul 11 2006 & $0.05(0.91)$ & $-1.19(0.32)$ & $-0.06(0.73)$ & $0.83(0.42)$ \\
DT 7.5\% May 29 2007 & $-0.37(0.81)$ & - & $-0.89(0.87)$ & $0.04(0.46)$ \\
DT 6.125\% Dec 4 2007 & $-0.34(0.62)$ & - & $-1.01(0.23)$ & $-0.26(0.61)$ \\
DT 5.75\% Feb 12 2008 & $-1.51(1.22)$ & - & $-2.68(0.77)$ & $-1.13(1.10)$ \\
DT 6.5\% Oct 7 2009 & $-2.73(1.90)$ & - & $-4.06(1.60)$ & $-1.69(1.40)$ \\
FT 5.75\% Mar 14 2004 & $0.53(0.62)$ & $0.62(0.47)$ & $0.43(0.68)$ & $0.57(0.65)$ \\
FT 5\% Feb 26 2005 & $-0.05(0.65)$ & $-0.01(0.14)$ & $-0.42(0.70)$ & $0.41(0.12)$ \\
FT 6.75\% Mar 14 2008 & $1.20(1.64)$ & $-0.33(1.06)$ & $1.63(1.64)$ & $2.25(0.79)$ \\
\hline
\end{tabular}

Table 2: Estimated market values (in \% of face value) of the step-up provisions. Average (and standard deviation) of daily observations. The market value is computed as the market price minus the theoretical value of the regular cash flow valued on a firm-specific zero-coupon yield curve. The regular cash flow is defined as the remaining part of the initially scheduled payments plus a potentially already triggered step-up payment at the next coupon date.

many cases even negative - which can apparently not be attributed to differences in traditional liquidity measures. These model-independent observations provide some evidence of underpricing in the periods before step-ups have been activated. To address this issue in the entire sample and to give quantitative estimates, we need a rating-based pricing model.

\section{A rating-based model}

We apply the model of JLT which is a natural framework to handle the explicit rating-dependence of the step-up provisions. We also considered valuing the provisions by modelling the companies' EDF (i.e. the expected default frequencies used by Moody's/KMV) - a measure of credit quality based on a modified structural approach originating from Merton (1974). Rating transitions could then be specified as the EDF (or a smoothed version of the EDF) crossing certain thresholds, and the EDF could serve as the default intensity. This was however not possible in our case for two reasons. First, there is no clear consistent mapping from the EDF (or a smoothed version of the EDF) to credit rating. As can be seen from Figure 3, the actual rating and the EDF-implied rating (using the $\mathrm{EDF} /$ rating mapping shown on EDF graphs) deviate by as much as 3-6 rating classes for more than a year. Second, using the EDF as default intensity would be out of line with bond market prices. For FT, the EDFs where much higher than the implied default intensities in the bond market after June 2002. A possible explanation for the huge difference between the default probability implicit in the 

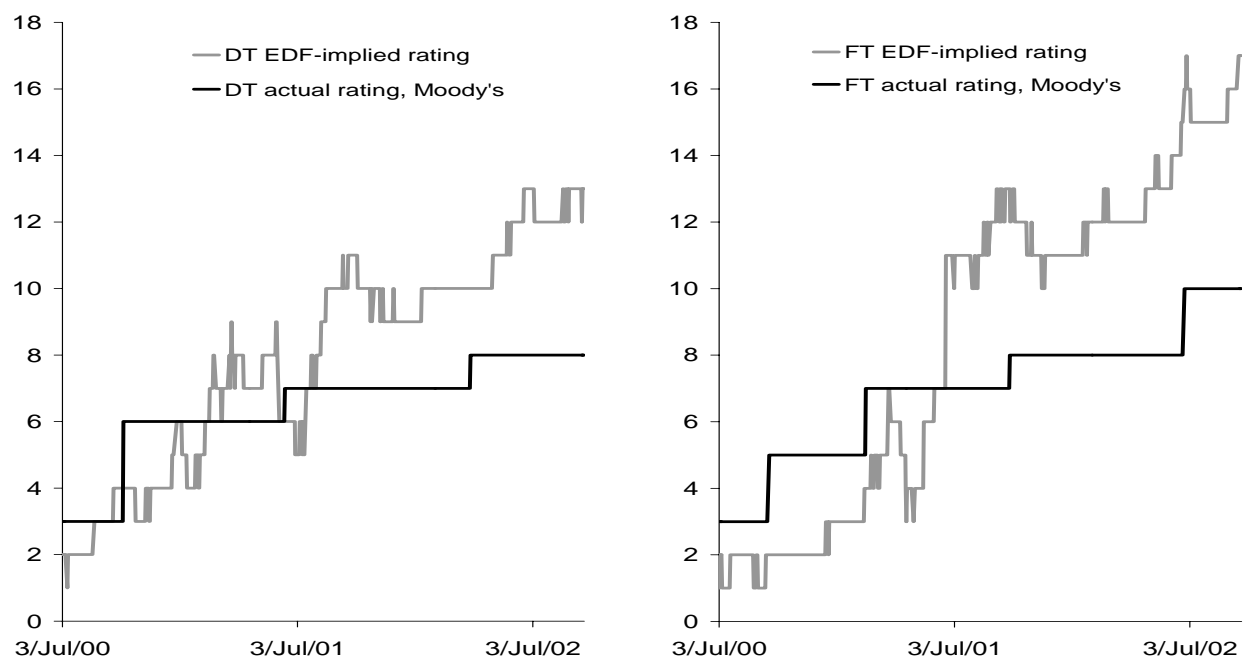

Figure 3: Actual ratings vs. EDF-implied ratings. EDF is Moody's/KMV's expected default frequency. The vertical axis gives the rating category: $1=$ Aaa, $2=$ Aa $1, \ldots, 17=$ Caa, $18=$ D. The EDF-implied ratings have been obtained using the EDF/rating mapping shown on EDF graphs. Source: Moody's/KMV.

equity market and in the debt market is that the perception of 'too big to fail' and the possible government support affects equity- and bondholders asymmetrically. In that case, the default probabilities implied from the debt market are more reliable. Hence, we base our analysis on debt market observations.

We consider a filtered probability space $\left(\Omega, \mathcal{F}_{\bar{T}},\left\{\mathcal{F}_{t}\right\}_{0 \leq t \leq \bar{T}}, P\right)$, where the filtration is defined later. We assume the existence of an equivalent martingale measure, $Q$, under which all pricing is done, which is essentially equivalent to assuming absence of arbitrage. In the JLT model the rating process, denoted by $\eta_{t}$, is a Markov ${ }^{7}$ chain with discrete state space given by the rating categories $1, \ldots, K$, where 1 refers to the highest rating category and $K$ refers to default. In the discrete-time version applied here, the Markov chain is governed by the

\footnotetext{
${ }^{7}$ In practise, ratings are likely to violate the Markov property. There is evidence of rating momentum - Bangia et al. (2002) and Lando and Skødeberg (2002) report that recently downgraded/upgraded issuers tend to have an increased/decreased probability of downgrade and default. We take the Markov setting as an approximation. A non-Markovian model, calibrated to the same reference bond prices, would attach more value to the step-up provisions in default scenarios, stemming from more gradual defaults relative to immediate defaults. On the other hand, non-default scenarios would give relatively more probability mass to non-downgrade scenarios. The total effect of non-Markovian ratings on the value of step-up provisions will depend on the language of the step-up clause and whether it has already been triggered or not, and is likely to be small.
} 
rating transition probability matrices under $Q$

$$
Q(t, t+n)=\left[q_{i j}(t, t+n)\right]_{i, j=1, \ldots, K}
$$

where $q_{i j}(t, t+n)=Q\left(\eta_{t+n}=j \mid \eta_{t}=i\right)$ is the risk-neutral probability of a rating migration from $i$ at time $t$ to $j$ at time $t+n$. All rows sum to unity, $\sum_{j=1}^{K} q_{i j}(t, t+n)=1$, and the default probabilities are found in the $K$ 'th column. The $K$ 'th row of the matrix has 1 in the diagonal, since we assume that default is an absorbing state. ${ }^{8}$ The multi-period rating probabilities of the Markov chain are obtained from the one-period probabilities by $Q(t, t+n)=\prod_{i=1}^{n} Q(t+i-1, t+i) .^{9}$ In Section 4 we will discuss the estimation of the risk-neutral as well as the realworld rating transition probabilities denoted by $P(t, t+n)=\left[p_{i j}(t, t+n)\right]_{i, j=1, \ldots, K}$.

Denote by $\tau$ the time of default, i.e. the absorbtion time of the Markov chain. In the event of default we assume a fractional recovery of face value, $\delta$, paid at the time of default. ${ }^{10}$ Recovery of face value at default is a good approximation to the legal practise in liquidation and finds empirical support in a recent study by Guha (2003). We put $\delta=0.44$ consistent with Moody's average recovery for senior unsecured claims in the period 1982-2000 (Hamilton, Cantor, and $\mathrm{Ou}(2002)$ ), measured as the bond price one month after default as a fraction of principal. Das and Tufano (1996) extend the model by allowing stochastic recovery rates and thereby capture the realistic feature of stochastic credit spreads within rating categories. As we shall see, we allow for different credit spreads within the same rating categories from two sources. We adjust the transition probabilities for rating outlook, and we calibrate the transition probabilities to the spread of the specific issuer, although we do not set up a stochastic model for it. ${ }^{11}$ We prefer adjusting the rating probabilities instead of adjusting the recovery rates, since it seems more plausible that investors constantly revise their default probabilities than their recovery expectations, at least for investment grade issuers. Moreover, we include multiple issues of the same issuer and priority, and therefore we must require identical recovery rates across bonds.

The default-free term structure of interest rates can be specified by any arbitrage-free model, and the value at time $t$ of the bank account is denoted by $B_{t}$. The cash flows we will be evaluating depend on the rating processes

\footnotetext{
${ }^{8}$ The recovery payment at the time of absorption corresponds to the post-default marked value of the claim. This value in turn reflects investors' expectations of a future recovery payment in liquidation or after a possible restructuring process.

${ }^{9}$ Probabilities at non-integer dates are found by linear interpolation.

${ }^{10}$ The recovery rate need not be constant, but must be uncorrelated with interest rates and default times. For stochastic recovery, $\delta$ denotes the (risk-neutral) expected recovery.

${ }^{11}$ We could incorporate the stochastic behavior of transition probabilities and specify stochastic credit spreads within a fixed rating class along the lines of Lando (1998). However, since our focus is on the relative pricing of the step-up bonds compared to the bonds with no such provisions, we believe that the effect of stochastic fluctuations in spreads within a class are likely to be second-order compared to the effect of credit class migration which is captured in our approach.
} 
of both Moody's and S\&P denoted by $\eta^{M}$ and $\eta^{S}$, respectively. Define the filtration, $\left\{\mathcal{F}_{t}\right\}_{0 \leq t \leq \bar{T}}$, as the natural filtration generated by the rating processes and the state variables driving the default-free term structure of interest rates, and let conditional probabilities and expectations with respect to $\mathcal{F}_{t}$ under the risk-neutral measure be denoted by $Q_{t}(\cdot)$ and $E_{t}^{Q}(\cdot)$, respectively. The price at time $t$ of a default-free zero-coupon bond maturing at time $t_{m}$ (less than $\bar{T}$ ) is $B\left(t, t_{m}\right)=E_{t}^{Q}\left[B_{t} / B_{t_{m}}\right]$

As in JLT, we assume independence between the rating process and the interest rate process under $Q .{ }^{12}$ Assume that a relevant issuer is rated $\eta_{t}^{M}=i$ and $\eta_{t}^{S}=j$. The time- $t$ price of a risky coupon bond, $C^{(i, j)}\left(t, t_{m}\right)$, maturing at $t_{m}$ with coupon payments $c$ at the remaining coupon dates $t_{1}<t_{2}<\cdots<t_{m}$ is given by the expected value under the risk-neutral measure of the discounted promised cash flow plus the recovery payment in the event of default

$$
\begin{gathered}
C^{(i, j)}\left(t, t_{m}\right)=\sum_{n=1}^{m} c B\left(t, t_{n}\right) Q_{t}\left(\tau>t_{n}\right)+B\left(t, t_{m}\right) Q_{t}\left(\tau>t_{m}\right) \\
+E_{t}^{Q}\left[\delta \frac{B_{t}}{B_{\tau}} \mathbf{1}_{\left\{\tau \leq t_{m}\right\}}\right]
\end{gathered}
$$

\subsection{Step-up bonds}

A step-up bond can be decomposed into an otherwise identical fixed-coupon bond and the step-up cash flow: $C_{\text {step }}^{(i, j)}\left(t, t_{m}\right)=C^{(i, j)}\left(t, t_{m}\right)+S^{(i, j)}\left(t, t_{m}\right)$. The value of the step-up cash flow for the FT step-up bonds maturing in 2004 and 2008 is

$$
S^{(i, j)}\left(t, t_{m}\right)=E_{t}^{Q}\left[\sum_{n=1}^{m} \mathbf{1}_{\left\{\tau>t_{n}\right\}} f\left(\eta_{t_{n-1}}^{M}, \eta_{t_{n-1}}^{S}\right) \frac{B_{t}}{B_{t_{n}}}\right]
$$

where $t_{0} \leq t$ is the previous coupon date (if it exists), and $f(i, j)$ is the step-up coupon defined by the provisions. For these two issues $f(i, j)=0.0025[i-7]^{+}+$

\footnotetext{
${ }^{12}$ Longstaff and Schwartz (1995), Duffee (1998) and Collin-Dufresne, Goldstein, and Martin (2001) provide evidence that credit spreads are negatively correlated with interest rates, most significantly for lower credit qualities and longer maturities. Duffee (1999) also reports signs of negative correlation, although of much less significance. We apply the independence assumption as an approximation, which could be relaxed using the generalized Markov chain model of Lando (1998). For the purpose of pricing step-up bonds relative to similar fixedcoupon bonds, the correlation effect is likely to be very small. Lando (1994) shows that assuming independence, if the true correlation is negative (and if interest rates are positively serially correlated), implies upward-biased bond prices. This goes for both types of bonds, and in the case of negative correlation the independence assumption gives a slightly conservative estimate of the theoretical value of step-up provisions, since the states of nature with step-up payments would have a tendency to be associated with low interest rates. Furthermore, the empirical evidence of negative correlation is based on bond indices or pools of bonds. The sign of the correlation for the assets and liabilities of a specific company is not obvious.
} 
$0.0025[j-7]^{+}$, since A3/A- corresponds to $i=j=7$ in the rating systems with 18 categories. Thus,

$$
\begin{aligned}
S^{(i, j)}\left(t, t_{m}\right) & =0.0025 B\left(t, t_{1}\right)\left(\left[\eta_{t_{0}}^{M}-7\right]^{+}+\left[\eta_{t_{0}}^{S}-7\right]^{+}\right) Q_{t}\left(\tau>t_{1}\right) \\
& +\sum_{n=2}^{m} 0.0025 B\left(t, t_{n}\right) \sum_{k=8}^{K-1}[k-7] Q_{t}\left(\eta_{t_{n-1}}^{M}=k\right) Q_{t}\left(\tau>t_{n} \mid \eta_{t_{n-1}}^{M}=k\right) \\
& +\sum_{n=2}^{m} 0.0025 B\left(t, t_{n}\right) \sum_{l=8}^{K-1}[l-7] Q_{t}\left(\eta_{t_{n-1}}^{S}=l\right) Q_{t}\left(\tau>t_{n} \mid \eta_{t_{n-1}}^{S}=l\right)
\end{aligned}
$$

The step-up issues of DT and the FT 2005 issue are, as mentioned, complicated by their path-dependent step-down structure. Initially, a step-up is triggered for a coupon date if both ratings are downgraded to the trigger level at the previous coupon date. Subsequent to a step-up, step-down is triggered if both ratings are above the trigger level at a later coupon date. Therefore, in case of a split rating $\left(\eta^{M} \neq \eta^{S}\right)$ across a trigger level, the two ratings are not sufficient to determine the coupon payment at the next coupon date - the information of the level of step-up triggered at the previous coupon date is also needed. This path-dependence can be eliminated by including an extra state variable. Let $u_{t_{n}}$ denote the amount of step-up triggered at the date $t_{n}$ for the payment date $t_{n+1}$. Then $u_{t_{n}}$ is a function of its previous value and the ratings at $t_{n}, u_{t_{n}}=f\left(u_{t_{n-1}}, \eta_{t_{n}}^{M}, \eta_{t_{n}}^{S}\right)$, and the value of the step-up cash flow is

$$
S^{(i, j)}\left(t, t_{m}\right)=E_{t}^{Q}\left[\sum_{n=1}^{m} \mathbf{1}_{\left\{\tau>t_{n}\right\}} f\left(u_{t_{n-2}}, \eta_{t_{n-1}}^{M}, \eta_{t_{n-1}}^{S}\right) \frac{B_{t}}{B_{t_{n}}}\right]
$$

where $t_{-1}<t_{0} \leq t$ are the previous coupon dates (if they exist). The details of computing this expected value and the precise definition of the function $f$ in the path-dependent cases can be found in Appendix B.

The value of the provisions can be approximated by ignoring the path-dependence and assuming no step-up at the previous coupon date $(u=0)$. This gives a provision value that is always lower than the value obtained by including the path-dependence (since $f(u, k, l) \geq f(0, k, l)$ for all $u, k$ and $l$ ), but the step-up payments only differ for possible step-downs in cases with split ratings across the trigger level. This occurs with low probability unless it is the initial state. To illustrate the difference, the FT 2005 step-up provision has a (base case) theoretical value of 0.164 at issuance, whereas the approximation ignoring the pathdependence gives rise to the slightly lower value 0.162 . The difference, however, is large if the initial state is a split rating across a trigger level. At the end of the sample, FT has the split rating Baa3/BBB, and the (base case) provision value is 0.732 versus 0.599 ignoring the path-dependence. Therefore, implementing the precise structure of the provisions is important. 


\subsection{Split ratings and rating correlation}

The DT step-up bonds and the FT 2005 step-up bond are defined on rating events involving both Moody's and S\&P. The two agencies' ratings of the same company are obviously positively correlated but split ratings are often observed. As mentioned, the value of the provisions can be seriously affected by split ratings. Thus, it is important to account for split ratings and rating correlation in the model. The natural way to incorporate correlated ratings is to enlarge the state space of the Markov chain to $K^{2}$ states, which could reasonably be reduced since most of the states would be highly unlikely - split ratings of more than, say, two notches are rare and usually only observed in short time intervals. The problem, however, is estimating the joint rating transition probabilities. To circumvent this problem, we will make a simplifying assumption which gives a reasonable approximation of the step-up values.

It is often observed that the rating of one agency adapts to the rating of the other agency. We simply assume a fixed (risk-neutral) probability, A, of adaption at the end of each one-year period. In case of adaption, we assume that the two rating agencies have equal probabilities of being the leader and the follower. That is, with probability $\mathrm{A}$, the ratings migrate from $(i, j)$ to $(k, k)$ with probability $\frac{1}{2} q_{i k}^{M}(t, t+1)+\frac{1}{2} q_{j k}^{S}(t, t+1)$. With probability $1-A$, the ratings do not adapt. In this case, we conjecture that the ratings migrate independently from $(i, j)$ to $(k, l)$ with probability $q_{i k}^{M}(t, t+1) \cdot q_{j l}^{S}(t, t+1)$. Note that in both cases, and thus in total, the probabilities sum to one. We set $A=0.8$ to reflect that the agencies agree most of the time. This is admittedly arbitrary but in Section 5.2 we demonstrate that the conclusions are insensitive to this parameter.

\section{The rating transition probabilities}

In the pricing of rating-sensitive assets we need to assess the likelihood of future rating migrations - not just the default probabilities. The historical rating transition matrices published by the rating agencies contain valuable information about an average firm in an average state of the economy, but we need risk-neutral rating probabilities for a specific issuer at a specific point in time. To obtain that, we first modify the historical rating matrix according to the firm-specific rating outlook. Next, the risk-neutral rating matrix is obtained through a calibration to the implied default probabilities in observed (fixed-coupon) bond prices, which at the same time ensures firm- and time-specific probabilities. We discuss existing methods and propose a new method for calibrating the rating-based model to implied default probabilities. For notational simplicity the time-dependence of the rating transition matrices is suppressed throughout this section. 


\subsection{Rating outlook}

In addition to the ratings, the rating agencies assign a rating outlook which is important for the valuation of step-up provisions. An unstable outlook can be interpreted as being in between two rating classes. We account for the rating outlook by adjusting the first-year rating transition matrix in the relevant row, $i$, in the following way ${ }^{13}$

$$
\tilde{p}_{i j}= \begin{cases}(1-\xi) p_{i j}+\xi p_{i-1, j} & \text { if positive outlook } \\ (1-\xi) p_{i j}+\xi p_{i+1, j} & \text { if negative outlook }\end{cases}
$$

for $j=1, \ldots, K$, where $\xi \in(0,1)$. Some statistics on the population of firms with unstable rating outlook are available from Keenan, Fons, and Carty (1998). Using the default frequencies from this source, we estimate $\xi=0.53$ for the statements 'review for possible up-/downgrade' from Moody's. We use the same parameter value for the statements 'positive/negative watch' from S\&P. For the weaker statements 'negative/positive outlook' from both agencies, we choose $\xi=0.3$ as a plausible parameter value between 0 and 0.53 .

\subsection{Risk-neutral rating transition probabilities}

Economic theory tells us that assets positively correlated with aggregate consumption are attached with positive risk premia, and there is evidence that default (and downgrade) frequencies are counter-cyclical. Furthermore, the implied default probabilities (even after adjusting for non-default-related parts of the credit spreads) are usually higher than empirically observed default frequencies, and empirical findings of Elton et al. (2001) and Collin-Dufresne, Goldstein, and Martin (2001) suggest that credit spreads are to a relatively large extent driven by common systematic market factors. For these reasons we allow for risk premia in corporate bond spreads. The risk premium adjustments we propose may reflect either the sensitivity of the telecom issues to such systematic factors or a risk premium attributed to default of a telecom issuer which would have a profound impact on the European financial markets. In the following we do not distinguish between these two explanations.

One way of assessing the risk-neutral rating transition probabilities is calibrating the rating-based model to corporate bond prices. Different low-dimensional,

\footnotetext{
${ }^{13}$ The step-up cash flows do not explicitly depend on rating outlooks but still the rating transition probabilities should be affected by the initial outlook. Therefore, we choose to simply adjust the first-year transition matrix, instead of incorporating outlooks as additional states in the Markov chain. This corresponds to randomizing the initial state in the Markov chain across the states $i-1, i$ and $i+1$. A company can be assigned an unstable outlook for more than one year but adjusting the first-year probabilities also alters the cumulative probabilities at longer horizons.
} 
parametric risk adjustments of the empirical transition matrix have been proposed. The purpose of these adjustments is to avoid implying out all the parameters of the risk-neutral transition probability matrix. Implying out all parameters from scratch is not possible from the observed data, and it would disregard any information about the structure of the risk-neutral transition probabilities which one would expect to be contained in the empirical transition probabilities. However, the particular choice of parametric risk adjustment significantly affects the non-default probabilities in the risk-neutral transition matrix, and therefore it is important to have a numerically stable and economically meaningful calibration method.

The method we are going to propose has the advantage of adjusting the risks of downgrade and default in the same direction (upwards) and the probability of upgrade in the opposite direction. This is consistent with thinking of rating changes as occurring when the issuer's assets cross certain thresholds and assuming that assets have a higher positive drift under the empirical probability measure than under the risk-neutral measure. The fact that risk-neutral upgrade and downgrade probabilities are adjusted in opposite directions also is more consistent with the way we think of the risk-adjustment as possibly capturing a deviation in the issuer-specific transition matrix from the sector- or industry-wide matrix used for calibration. If, for example, the market believes that a particular company is riskier than what is implied by its current rating, then the market may price the issuer's debt using larger downgrade probabilities and smaller upgrade probabilities simply because the market believes the empirical transition probability for the issuer is different. The calibration method we propose is consistent with such a pricing behavior.

We give a brief review of the methods proposed in the literature before we propose our new method. JLT propose the following adjustment

$$
q_{i j}= \begin{cases}\theta_{i} p_{i j} & \text { for } j \neq i \\ 1-\theta_{i}\left(1-p_{i i}\right) & \text { for } j=i\end{cases}
$$

for $i=1, \ldots, K-1$ and $j=1, \ldots, K$. This method effectively speeds up/down the rating process. In each row, it implies that upgrade and default entries are adjusted in the same direction, which is counter-intuitive. Unfortunately, extremely high $\theta$ 's are often needed, since the empirical default probabilities are very low for high credit ratings and even zero in some cases, making the method infeasible, as we shall see in an example below. ${ }^{14}$ Also, small changes in the uncertain empirical estimates of high grade default probabilities lead to extremely high changes in risk adjustments.

KK address the numerical problems with the method of JLT and propose the

\footnotetext{
${ }^{14}$ The problems arise because the method is based on a discrete-time approximation of the transition matrix from the generator matrix. For more on this, see Lando (2004).
} 
following alternative adjustment

$$
q_{i j}= \begin{cases}\theta_{i} p_{i j} & \text { for } j \neq K \\ 1-\theta_{i}\left(1-p_{i K}\right) & \text { for } j=K\end{cases}
$$

This proves to be numerically stable, but it implies counter-intuitively that default and downgrade entries are adjusted in opposite directions. ${ }^{15}$ More realistic adjustments, taking the same direction for downgrade and default and the opposite for upgrade, could easily be obtained by introducing one adjustment factor for upgrades and another for downgrades, where the latter factor is e.g. the inverse of the former. But instead of this technical modification of the KK method we seek a functional form for the adjustments inspired by economic theory as explained in the following.

Consider a one-period model from $t$ to $t+1$ with discrete state space given by the $K$ rating classes, which is of course highly restrictive but only used to motivate a functional form for the calibration. Let $i$ be the initial state. Assume that all agents ${ }^{16}$ have utility from (consuming) wealth according to the power utility function $u(w)=\frac{w^{1-\theta}}{1-\theta}$, implying a constant relative risk aversion of $\theta$. The traded assets are the riskless bank account and a risky $T$-period zero-coupon bond priced $V_{i}(t)$. Assume furthermore a constant riskless interest rate, $r$, and constant credit spreads, $s_{j}$, in each of the rating classes. Then $V_{j}(t)=e^{-\left(r+s_{j}\right) T}$. By the end of the period, the state of the world is $j$ with real-world probability $p_{i j}$, for $j=1, \ldots, K$.

It is well-known that the first order condition for utility-maximizing agents is an Euler equation implying that the state price density is proportional to the marginal utility given optimal investment. In our setting this means

$$
\frac{q_{i j}}{p_{i j}}=\kappa u^{\prime}\left(w_{j}(t+1)\right)=\frac{u^{\prime}\left(w_{j}(t+1)\right)}{\sum_{k=1}^{K} p_{i k} u^{\prime}\left(w_{k}(t+1)\right)}
$$

for $j=1, \ldots, K$, where the wealth in state $j$ at time $t+1$ is

$$
w_{j}(t+1)=a_{i} w_{i}(t) \frac{V_{j}(t+1)}{V_{i}(t)}+\left(1-a_{i}\right) w_{i}(t) e^{r}
$$

\footnotetext{
${ }^{15}$ Furthermore, the method does not ensure that the real-world and risk-neutral probability measures are equivalent, but this is of no importance if zero-entries in the empirical transition matrix are considered as poor estimates of very small probabilities of rare events. Moreover, this applies to any method modifying empirical zero-probabilities into strictly positive implied probabilities.

${ }^{16}$ We do not assume the presence of a representative agent, since we do not assume complete markets.
} 
and $a_{i}$ denotes the optimal fraction of wealth invested in the risky asset. ${ }^{17}$ Then

$$
\frac{q_{i j}}{p_{i j}}=\frac{\left[1-a_{i}\left(1-e^{s_{j}+\left(s_{i}-s_{j}\right) T}\right)\right]^{-\theta}}{\sum_{k=1}^{K} p_{i k}\left[1-a_{i}\left(1-e^{s_{k}+\left(s_{i}-s_{k}\right) T}\right)\right]^{-\theta}}
$$

for $j=1, \ldots, K$. Note that the Radon-Nikodym derivative is independent of initial wealth and the interest rate level. This is the functional form we propose to use.

A more realistic setting would allow more states of nature, heterogenous agents, multiple risky assets and time periods, and stochastic interest rates and credit spreads. In practical application, however, we hope that the functional form of the risk-adjustments in the stylized setting still provides a good approximation. As we shall see, the adjustments from (9) certainly seem more reasonable than the adjustments from the methods of JLT and KK.

Table 3 presents numerical examples, for simplicity in the rating system with 8 categories. Suppose we calibrate a Baa-rated 5 -year bond to an implied annual default probability of $1.5 \%$ (which is roughly the level observed for DT in the relevant rating class, after subtracting a liquidity spread). The real-world rating transition probabilities are from Moody's, and the credit spreads are given by historical average levels. ${ }^{18}$ We test three different values for the optimal fraction of wealth invested in the bond, $a$, and in each case the parameter $\theta$ is set to fit the implied default probability $(j=K$ in $(9))$ and then used to obtain the risk-neutral non-default probabilities $(j \neq K$ in $(9))$. Fortunately, the method is remarkably stable with respect to the parameter $a$. Considering the uncertainty of the underlying estimates of the real-world probabilities, the differences in the adjusted probabilities are negligible, even for extreme variations in $a$. The same stability is evident from Figure 4 with respect to the bond maturity, $T$. The credit spreads in the different rating categories matter but they are, at least to some extent, approximately observable from market data. The parameter $\theta$ is sensitive to $a$ and $T$ and seems implausibly high - this does not indicate some kind of 'corporate bond premium puzzle', since $\theta$ is to be interpreted as an adjustment parameter, and not as a relative risk aversion, when we apply the method outside the stylized economy which was only considered for motivational purpose. As mentioned, the adjustment accounts for any discrepancy between

\footnotetext{
${ }^{17}$ To ensure internal consistency in the stylized economy, $a_{i}$ should be determined in agreement with $V_{i}(t)=\sum_{j=1}^{K} q_{i j} e^{-r} V_{j}(t+1)$. We are however not interested in the value of $a_{i}$, but only in the risk-adjustments, and they are as we shall see very insensitive to the value of $a_{i}$. Therefore, we do not apply this restriction on $a_{i}$.

${ }^{18}$ Historical default probabilities are from Hamilton, Cantor, and Ou (2002), corrected for withdrawn ratings. The investment grade spreads are consistent with Longstaff and Schwartz (1995), the speculative grade spreads with Caouette, Altman, and Narayanan (1998). The credit spread in default corresponds to a $50 \%$ recovery of Treasury with $r=5 \%$, i.e. $s_{K}$ satisfies $e^{-\left(r+s_{K}\right)(T-1)}=0.5 e^{-r(T-1)}$. Recovery of face value is inappropriate for zero-coupon bonds used for illustration in this stylized setting.
} 


\begin{tabular}{lrrrrrrrr}
\hline & Aaa & Aa & A & Baa & Ba & B & Caa & D \\
\hline$P$-probabilities, $p_{i j}(\%)$ & 0.05 & 0.26 & 5.45 & 88.55 & 4.72 & 0.72 & 0.09 & 0.16 \\
Credit spreads, $s_{j}(\mathrm{bp})$ & 50 & 80 & 120 & 180 & 300 & 450 & 900 & 1733 \\
Utility-based, $a=1(\theta=3.64)$ & & & & & & & & \\
$\quad Q$-probabilities, $q_{i j}(\%)$ & 0.04 & 0.22 & 4.88 & 86.57 & 5.50 & 1.04 & 0.25 & 1.50 \\
$\quad Q / P$-ratios, $q_{i j} / p_{i j}$ & 0.81 & 0.85 & 0.90 & 0.98 & 1.16 & 1.45 & 2.79 & 9.38 \\
Utility-based, $a=0.5(\theta=8.51)$ & & & & & & & & \\
$\quad Q$-probabilities, $q_{i j}(\%)$ & 0.04 & 0.21 & 4.80 & 86.42 & 5.65 & 1.10 & 0.28 & 1.50 \\
$Q / P$-ratios, $q_{i j} / p_{i j}$ & 0.78 & 0.82 & 0.88 & 0.98 & 1.20 & 1.53 & 3.08 & 9.38 \\
Utility-based, $a=0.01(\theta=479.48)$ & & & & & & & & \\
$\quad Q$-probabilities, $q_{i j}(\%)$ & 0.04 & 0.21 & 4.72 & 86.30 & 5.78 & 1.16 & 0.30 & 1.50 \\
$Q / P$-ratios, $q_{i j} / p_{i j}$ & 0.75 & 0.80 & 0.87 & 0.97 & 1.23 & 1.61 & 3.31 & 9.38 \\
JLT $(\theta=9.38)$ & & & & & & & & \\
$\quad Q$-probabilities, $q_{i j}(\%)$ & 0.47 & 2.44 & 51.09 & -7.34 & 44.25 & 6.75 & 0.84 & 1.50 \\
$Q / P$-ratios, $q_{i j} / p_{i j}$ & 9.38 & 9.38 & 9.38 & -0.08 & 9.38 & 9.38 & 9.38 & 9.38 \\
KK $(\theta=0.99)$ & & & & & & & & \\
$\quad Q$-probabilities, $q_{i j}(\%)$ & 0.05 & 0.26 & 5.38 & 87.36 & 4.66 & 0.71 & 0.09 & 1.50 \\
$Q / P$-ratios, $q_{i j} / p_{i j}$ & 0.99 & 0.99 & 0.99 & 0.99 & 0.99 & 0.99 & 0.99 & 9.38 \\
\hline
\end{tabular}

Table 3: Comparison of calibration methods. Implied one-year transition probabilities for Baa with an implied default probability of $1.5 \%$ and Moody's empirical transition probabilities. The utility-based method is applied with $T=5$, historical average credit spread levels, and three different values of $a$.

firm-specific implied market probabilities and the historical average probabilities - and not just risk premia.

For comparison, Table 3 also reports the implied probabilities obtained from the JLT and KK methods. As can be seen, the former is infeasible with the chosen discretization, and the adjustments of the utility-based method are more intuitive than those of the KK method. Note also, that no parameter restriction is needed to ensure non-negative probabilities in the utility-based method. However, as the JLT method, the utility-based method is very sensitive to the exact values of the real-world default probabilities. To alleviate this problem we apply a smoothed version of the empirical rating matrix, see Appendix C.

Having seen that the functional form suggested by the stylized economy provides more intuitive risk-neutral rating probabilities, we proceed with this method and perform robustness tests using the method of KK. Given the stability of the implied rating probabilities with respect to $a$ and $T$, it seems reasonable to apply (9) with $a=0.5$ and $T=5$, the latter representing the maturities we consider reasonably well. That is, we apply

$$
\frac{q_{i j}(t, t+1)}{p_{i j}(t, t+1)}=\frac{\left[1+e^{s_{j}+5\left(s_{i}-s_{j}\right)}\right]^{-\theta_{t+1}}}{\sum_{k=1}^{K} p_{i k}(t, t+1)\left[1+e^{s_{k}+5\left(s_{i}-s_{k}\right)}\right]^{-\theta_{t+1}}}
$$

for $j=1, \ldots, K$, with the credit spreads reported in Table 3 (for rating subcate- 

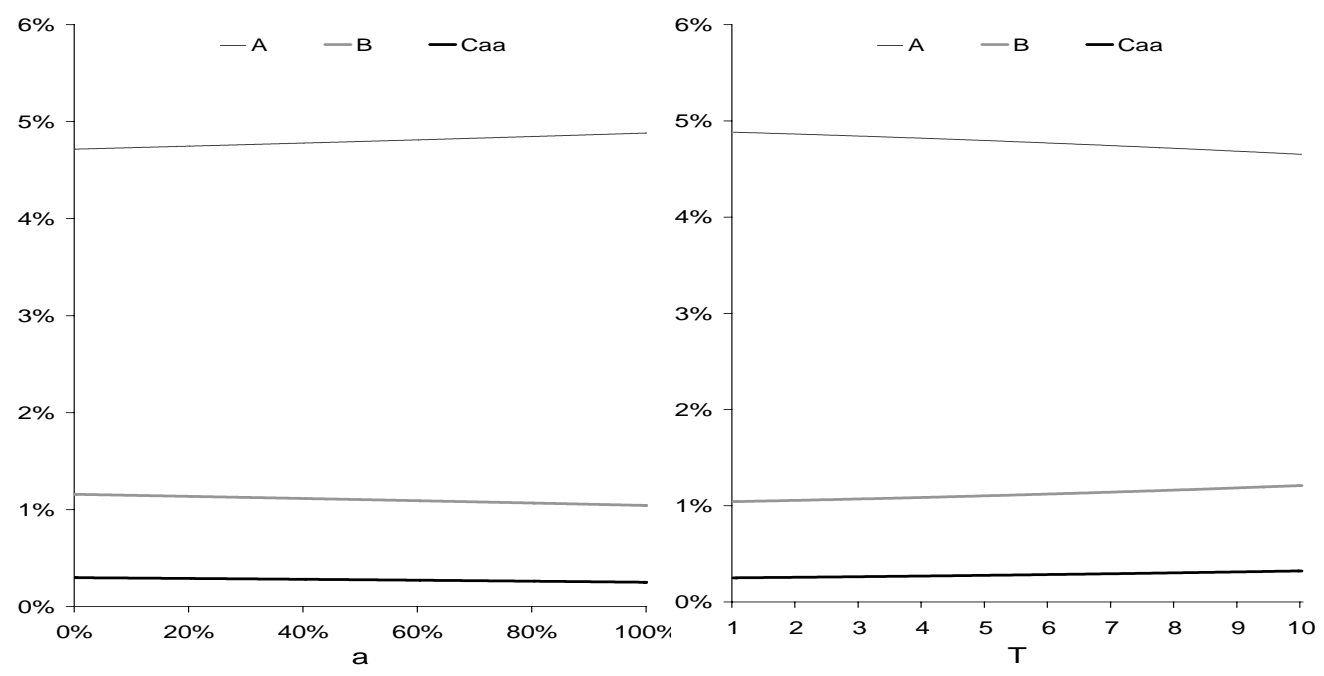

Figure 4: Implied rating transition probabilities from Baa to A, B and Caa. One-year probabilities as functions of $a$ (given $T=5$ ) and $T$ (given $a=0.5$ ) derived from the utility-based method for an implied Baa default probability of $1.5 \%$.

gories in the 18-ratings system, we interpolate the credit spreads). As in JLT and $\mathrm{KK}$, we let the parameter $\theta$ be time-dependent - the risk assessment of a specific firm (or point in time) relative to an average firm (or time period) is likely to vary with the time horizon - and adjust each of the one-year (forward) transition matrices.

\section{Results}

This section presents the results of our relative pricing analysis. We calibrate the rating-based model to the market prices of the reference bonds. Subsequently, the step-up provisions are valued using the derived issuer-specific default and rating probabilities. This procedure is repeated for each trading day in our sample. For Moody's we use the 18-ratings historical transition matrix for the period 19832001, published in Hamilton, Cantor, and Ou (2002). For S\&P we use the matrix based on the period 1981-2001, published in Standard and Poor's (2002). We corrected both matrices for 'withdrawn ratings'. To avoid the unreliable humps observed in the empirical matrices, we apply the smoothing method described in Appendix C.

Other factors than credit risk affect the yield spread between corporate bonds 
and government bonds. ${ }^{19}$ In the U.S. market, tax effects account for a part of the spread. ${ }^{20}$ Also, liquidity effects and convenience yields on Treasuries due to repo specialness are likely to affect the spread. ${ }^{21}$ The probability of default on AAA bonds in a short period of time is negligible. Thus, the short yield spread between AAA and government bonds can be regarded as a measure of the yield spread caused by other factors than credit risk. We add the spread between the 2-3year MSCI AAA Euro corporate bond index and the 2-year German benchmark government bond (the spread ranging from 12 to $44 \mathrm{bp}$ with an average of $29 \mathrm{bp}$ in our sample) to the German government bond yield curve to account for these factors.

To test the stability of our base case results in Section 5.1, Section 5.2 provides a series of robustness checks. In general, they support the conclusions drawn from the base case calculations. Finally, in Section 5.3, we investigate the capital structure implications of our findings.

\subsection{Base case results}

For each issuer and on each trading day, we calibrate the rating-based model to the reference bonds following (10). In doing that we face two practical problems. First, as mentioned, the universe of reference bonds is small, and we have to specify a structure between the maturities of the reference bonds. Second, some of the reference bonds have maturities close to each other which can cause an erratic term structure of adjustment parameters or even make exact calibration infeasible. To obtain a smooth structure of adjustment parameters, we use the following 2-parameter piecewise-linear structure in the base case calculations

$$
\theta_{t}= \begin{cases}\alpha_{1} & \text { for } t=1, \ldots, T_{1} \\ \frac{T_{2}-t}{T_{2}-T_{1}} \alpha_{1}+\frac{t-T_{1}}{T_{2}-T_{1}} \alpha_{2} & \text { for } t=T_{1}+1, \ldots, T_{2}-1 \\ \alpha_{2} & \text { for } t=T_{2}, \ldots\end{cases}
$$

where $T_{1}$ and $T_{2}$ are the maturities of the two earliest reference bonds rounded up to the next integer. ${ }^{22}$ That is, in periods with two reference bonds, we calibrate exactly to these two bonds, and in periods with more than two reference bonds, we minimize the quadratic price differences with respect to $\alpha_{1}$ and $\alpha_{2}$. We test two alternative fitting procedures in the robustness checks.

\footnotetext{
${ }^{19}$ Huang and Huang (2002) estimate that default risk only account for around $30 \%$ of the spread for Baa-issues.

${ }^{20}$ Elton et al. (2001) document that a substantial part of the spread (on the order of 30-40 bp) can be explained by corporate bonds being subject to state as well as government taxes in the U.S.

${ }^{21}$ Section 2 gave several references to empirical evidence on liquidity effects, and Jordan and Jordan (1997) document repo specialness effects.

${ }^{22}$ Rounding down or off to the closest integer instead gives essentially the same results.
} 

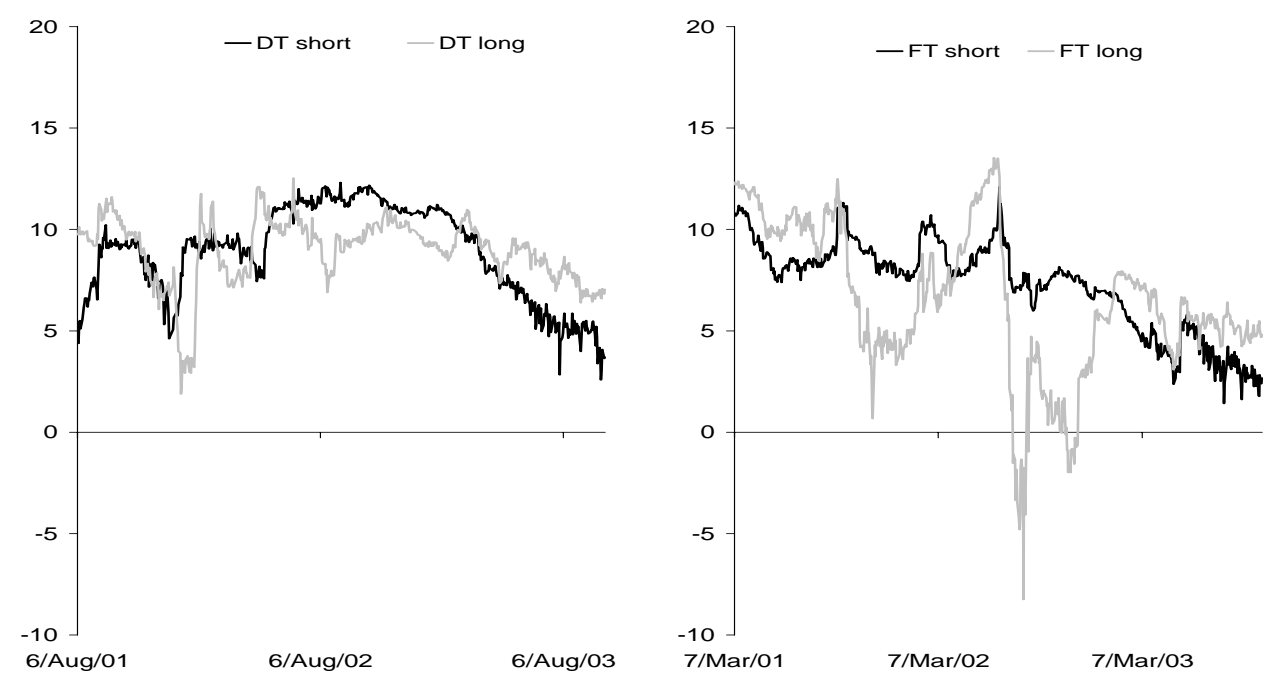

Figure 5: DT and FT bootstrapped risk-adjustment parameters. $\alpha_{1}$ (short) and $\alpha_{2}$ (long) derived from calibrating the model to reference bond market prices using (10) and (11), based on S\&P ratings and the smoothed S\&P transition matrix.

Figure 5 illustrates the risk-adjustment parameters derived for the two companies. The risk-adjustment parameters are volatile in periods with volatile yield spreads. The size of the parameters is unimportant and can be artificially scaled down (up) by increasing (decreasing) the parameter $a$, essentially without changing the implied probabilities as we saw in Section 4.2. The risk-adjustment is in general positive - only negative for long maturities in a few periods of the FT sample with substantially positive short maturity adjustment - indicating that default risk is positively priced. Note again that the parameters are not to be interpreted as relative risk aversions - e.g. a negative 10-year parameter only means that the market attaches lower default probability to the 10th year than implied by the empirical rating matrix (given a large upward adjustment of the short maturity default probabilities). The standard deviation on the reference bond price errors in the part of the sample with more than two reference bonds is 0.43 for DT and 0.30 for FT.

The market and model prices of the FT 2008 step-up bond are presented in the left panel of Figure 6, whereas the values of the step-up provisions are isolated in the right panel. As in Section 2, we define the step-up provision value to be the present value of any future payments in excess of the regular bond cash flow, where the regular cash flow includes the initially scheduled payments and a potentially already triggered step-up payment at the next coupon date. ${ }^{23}$ Hence,

${ }^{23}$ This definition corresponds to (2) and (3) excluding the first term, which represents the 

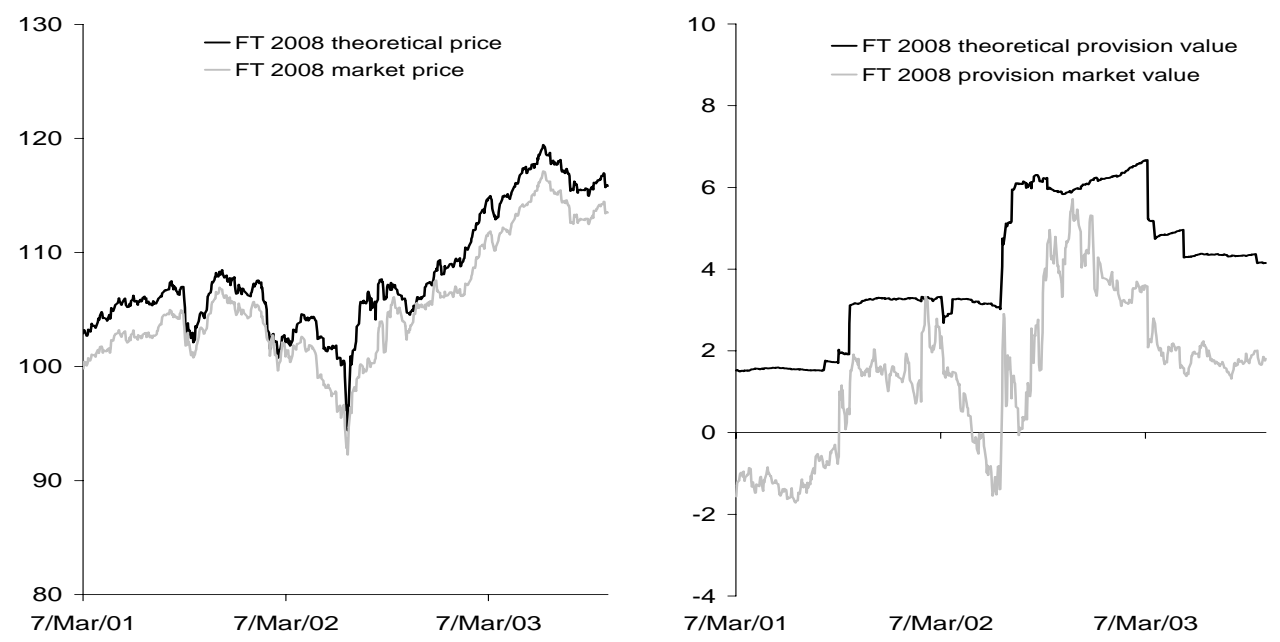

Figure 6: FT 2008 step-up bond, market and theoretical values. Theoretical prices are obtained from calibrating the model to the reference bond market prices using (10). The theoretical provision value is computed as the possible step-up payments in excess of the regular cash flow discounted by the state-prices from the calibrated model. The regular cash flow is defined as the remaining part of the initially scheduled payments plus a potentially already triggered step-up payment at the next coupon date. Market value is bond market price minus the theoretical value of the regular cash flow.

the theoretical value of the provisions is positive by definition. The market value of the provision is calculated as a residual: the market bond price minus the theoretical value of the regular cash flow. Therefore small changes in the firmspecific implied default probabilities translate into relatively large changes in the discounted regular cash flow, and thus in the provision market values. Figures 7 and 8 present similar results for other step-up provisions. The two DT step-up bonds not illustrated in the graphs follow a pattern similar to the two bonds in the bottom of Figure 8. The results confirm the first assessments made in Section 2: the market values attached to the provisions are volatile and low even negative in parts of the sample. In addition, the market values are almost throughout the sample less than the model values.

All the base case results are summarized in Table 4. Net present value (NPV) is defined as theoretical bond price minus market price. The FT provisions have higher theoretical and market values than the DT provisions due to the structure of the provisions. The market values correspond reasonably well with the modelindependent findings reported in Table 2. In most of the sample, the underpricing is economically significant - in some cases more than $2 \%$ of face value. At the end

potentially already triggered payment at the upcoming coupon date. 
of the sample, however, most of the NPVs have decreased markedly, and generally there is no significant underpricing. The FT 2008 step-up bond, however, still trades well below theoretical levels. It is important to note from Figure 7 that the NPV of the FT 2004 step-up bond collapsed in March 2003. This is not surprising given that the uncertainty of the cash flow disappears as the step-up bonds approach the penultimate coupon date (March 14, 2003, for the FT 2004 bond). Apparently, we start to see the same effect for some of the other step-up bonds.

One might be concerned that liquidity causes pricing differences between issues of the same issuer. We have however, as mentioned in Section 2, only included the most liquid bond issues of each issuer. Another worry could be that a potential credit-cliff - a phenomenon described in the introduction - may cause differences in the pricing of fixed-coupon bonds and step-up bonds. The pricing of step-up bonds is driven by recovery rates, rating probabilities and default probabilities. Fixed-coupon bonds and step-up bonds of the same issuer and priority must have identical recovery payments and default probabilities, but there could be a credit-cliff effect on the rating probabilities. It has to be very small, however, since the potential increase in liabilities is small, especially for DT. In turn, the impact on the relative pricing between step-up and fixed-coupon bonds has to be very small since default probabilities are the dominant factor. Furthermore, the negative step-up provision market values often observed cannot be explained by any alternative specification of rating transition probabilities. 

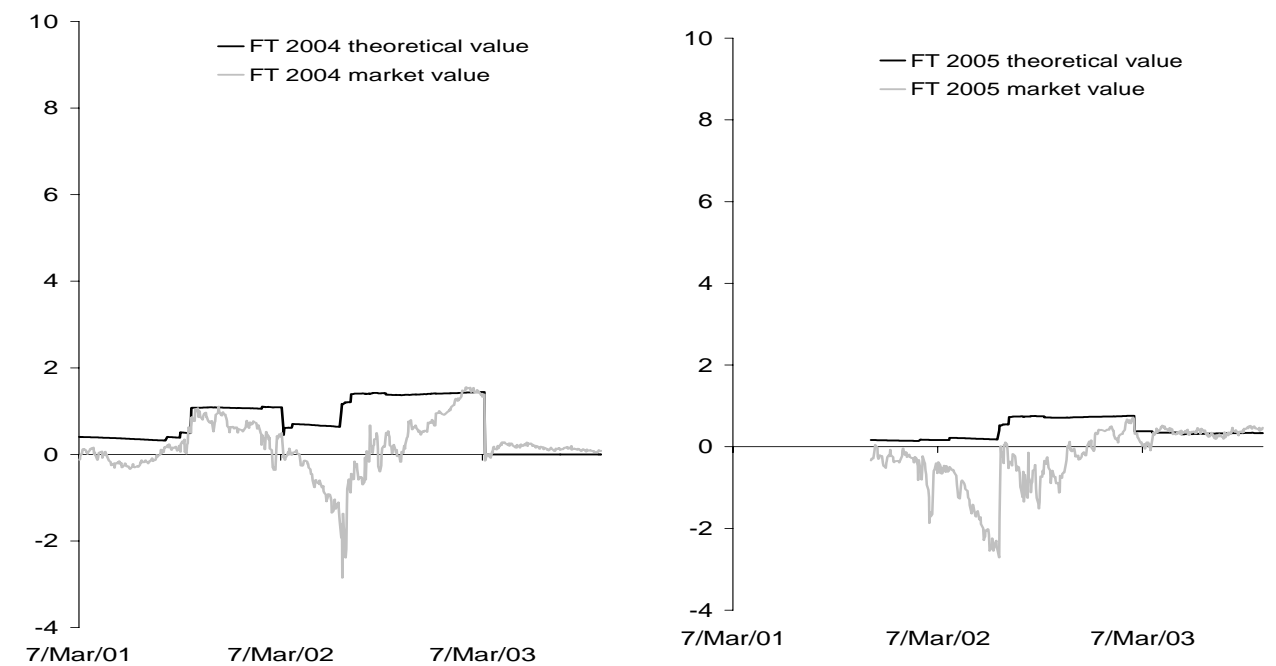

Figure 7: FT step-up provisions, market and theoretical values. The theoretical value is computed as the possible step-up payments in excess of the regular cash flow discounted by the state-prices from the calibrated model. The regular cash flow is defined as the remaining part of the initially scheduled payments plus a potentially already triggered step-up payment at the next coupon date. Market value is bond market price minus the theoretical value of the regular cash flow. 

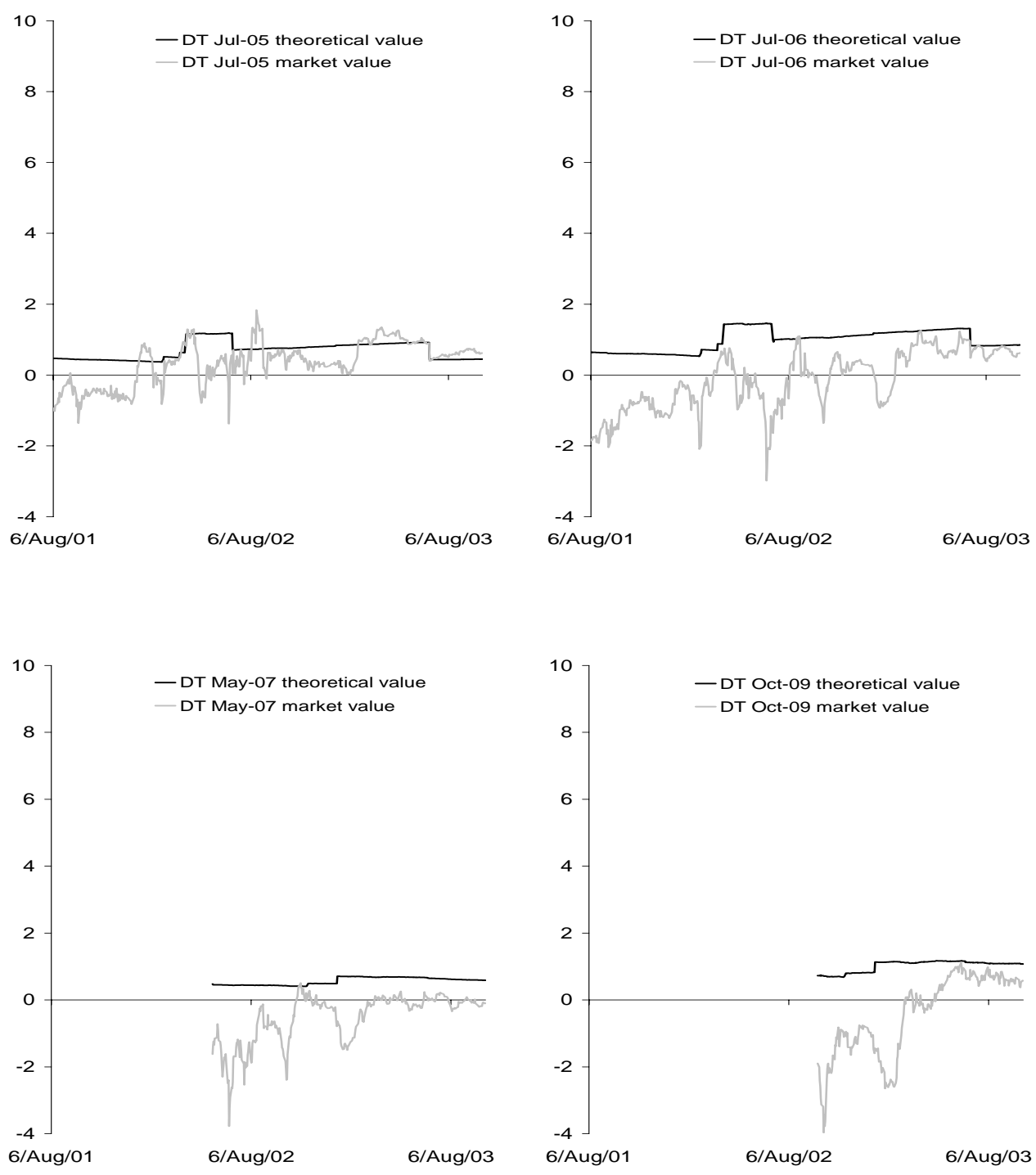

Figure 8: DT step-up provisions, market and theoretical values. The theoretical value is computed as the possible step-up payments in excess of the regular cash flow, discounted by the state-prices from the calibrated model. The regular cash flow is defined as the remaining part of the initially scheduled payments plus a potentially already triggered step-up payment at the next coupon date. Market value is bond market price minus the theoretical value of the regular cash flow. 


\begin{tabular}{|c|c|c|c|}
\hline & Theoretical value & Market value & NPV \\
\hline & \multicolumn{3}{|c|}{ Sub-sample 2001} \\
\hline DT $6.125 \%$ Jul 62005 & $0.43(0.02)$ & $-0.55(0.21)$ & $0.99(0.21)$ \\
\hline DT 5.875\% Jul 112006 & $0.60(0.02)$ & $-1.16(0.40)$ & $1.76(0.41)$ \\
\hline DT $7.5 \%$ May 292007 & - & - & - \\
\hline DT $6.125 \%$ Dec 42007 & - & - & - \\
\hline DT $5.75 \%$ Feb 122008 & - & - & - \\
\hline DT $6.5 \%$ Oct 72009 & - & - & - \\
\hline FT 5.75\% Mar 142004 & $0.60(0.33)$ & $0.23(0.43)$ & $0.38(0.17)$ \\
\hline FT 5\% Feb 262005 & $0.16(0.00)$ & $-0.27(0.14)$ & $0.42(0.13)$ \\
\hline \multirow[t]{2}{*}{ FT $6.75 \%$ Mar 142008} & $2.12(0.77)$ & $-0.17(1.27)$ & $2.30(0.59)$ \\
\hline & \multicolumn{3}{|c|}{ Sub-sample 2002} \\
\hline DT $6.125 \%$ Jul 62005 & $0.79(0.26)$ & $0.41(0.45)$ & $0.39(0.53)$ \\
\hline DT 5.875\% Jul 112006 & $1.06(0.30)$ & $-0.24(0.66)$ & $1.30(0.70)$ \\
\hline DT 7.5\% May 292007 & $0.45(0.02)$ & $-0.94(0.85)$ & $1.39(0.84)$ \\
\hline DT $6.125 \%$ Dec 42007 & $0.57(0.00)$ & $-0.88(0.18)$ & $1.45(0.18)$ \\
\hline DT $5.75 \%$ Feb 122008 & - & - & - \\
\hline DT $6.5 \%$ Oct 72009 & $0.75(0.05)$ & $-1.59(0.81)$ & $2.34(0.79)$ \\
\hline FT 5.75\% Mar 142004 & $1.11(0.31)$ & $-0.03(0.69)$ & $1.15(0.62)$ \\
\hline FT 5\% Feb 262005 & $0.46(0.27)$ & $-0.74(0.69)$ & $1.20(0.63)$ \\
\hline \multirow[t]{2}{*}{ FT $6.75 \%$ Mar 142008} & $4.64(1.41)$ & $2.09(1.88)$ & $2.55(1.47)$ \\
\hline & \multicolumn{3}{|c|}{ Sub-sample 2003} \\
\hline DT $6.125 \%$ Jul 62005 & $0.73(0.21)$ & $0.74(0.32)$ & $-0.01(0.31)$ \\
\hline DT 5.875\% Jul 112006 & $1.13(0.20)$ & $0.53(0.51)$ & $0.60(0.56)$ \\
\hline DT 7.5\% May 292007 & $0.66(0.05)$ & $-0.23(0.42)$ & $0.90(0.44)$ \\
\hline DT $6.125 \%$ Dec 42007 & $0.77(0.05)$ & $-0.27(0.55)$ & $1.04(0.56)$ \\
\hline DT $5.75 \%$ Feb 122008 & $0.82(0.03)$ & $-0.17(0.48)$ & $0.99(0.50)$ \\
\hline DT $6.5 \%$ Oct 72009 & $1.13(0.06)$ & $-0.04(1.07)$ & $1.17(1.06)$ \\
\hline FT 5.75\% Mar 142004 & $0.35(0.61)$ & $0.44(0.53)$ & $-0.09(0.14)$ \\
\hline FT 5\% Feb 262005 & $0.41(0.16)$ & $0.35(0.14)$ & $0.07(0.18)$ \\
\hline FT $6.75 \%$ Mar 142008 & $4.97(0.88)$ & $2.24(0.73)$ & $2.73(0.30)$ \\
\hline
\end{tabular}

Table 4: Market and theoretical step-up provision values. Average (and standard deviation) of daily observations. The theoretical value is computed as the possible step-up payments in excess of the regular cash flow discounted by the state-prices from the calibrated model. The regular cash flow is defined as the remaining part of the initially scheduled payments plus a potentially already triggered step-up payment at the next coupon date. Market value is bond market price minus the theoretical value of the regular cash flow. NPV is defined as theoretical value minus market value. 


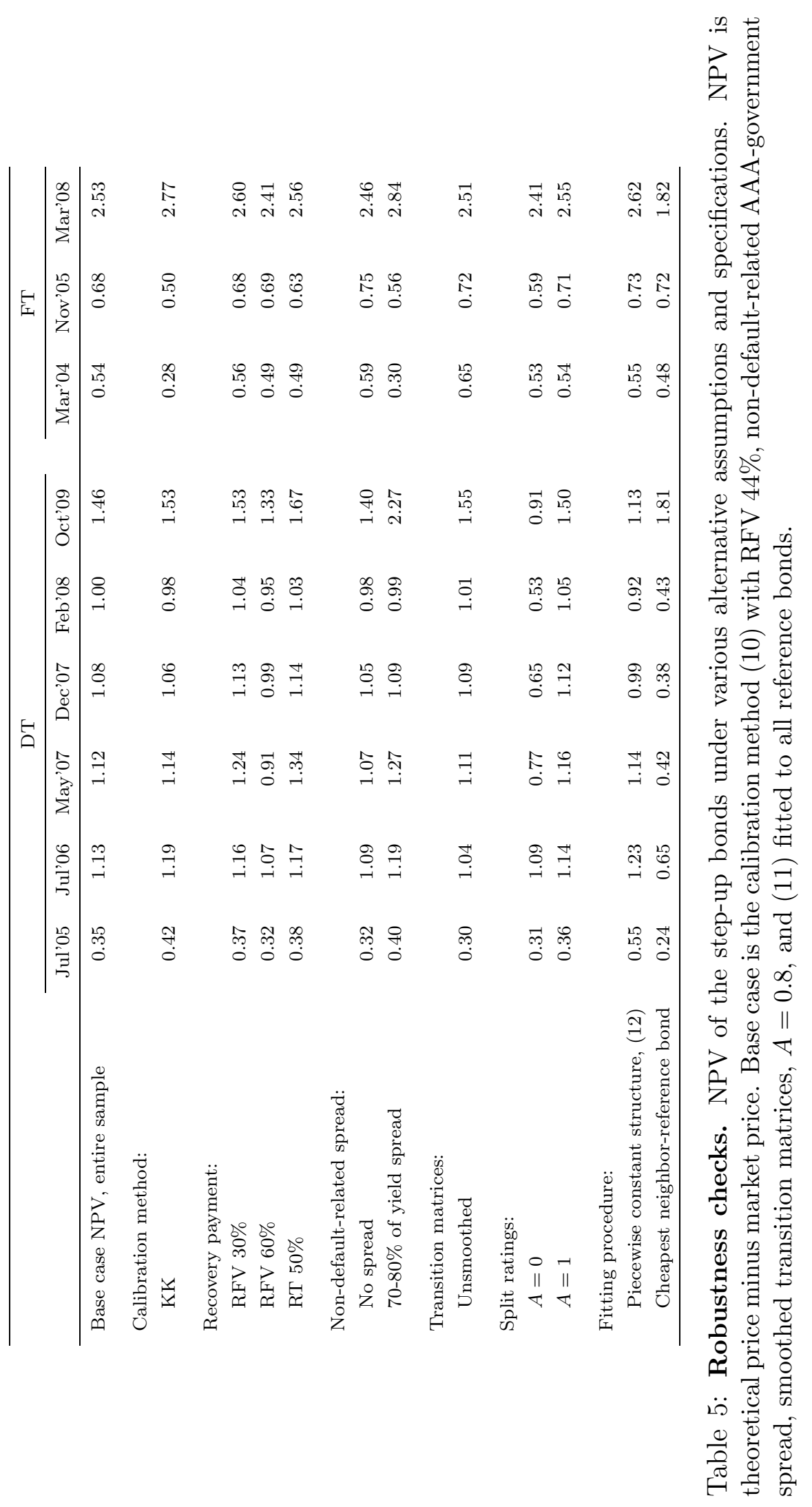




\subsection{Robustness checks}

To test the robustness of our results, we repeat the calculations with various alternative assumptions and specifications. The results of the robustness checks are found in Table 5. The tables only report the NPVs but the theoretical values of the step-up provisions are relatively stable across all specifications, and in most cases the differences in NPV mainly stem from differences in market values arising from changes in the implied default probabilities.

1. We compare our results with the KK calibration methods described in Section 4.2. From the NPVs, we conclude that the order of underpricing is largely the same as in the base case. The rest of the robustness checks are performed within the calibration framework (10).

2. We assumed a $44 \%$ recovery of face value (RFV) at default. Table 5 shows that the results are relatively insensitive to this parameter value - lower recovery rate means higher implied default probabilities, and the effect on fixed-coupon and step-up bonds is approximately the same. A lower recovery rate attaches slightly higher theoretical value to the step-up provisions, due to a higher upward adjustment of default and downgrade probabilities. As mentioned, the most realistic recovery assumption approximating legal practise in liquidation is RFV paid at the time of default. However, absolute strict priority may be violated in debt renegotiations in which case, as mentioned in Duffie and Singleton (1999), other recovery assumptions may be better approximations. They apply recovery of market value, whereas e.g. Jarrow and Turnbull (1995) and JLT apply recovery of Treasury (RT). We compare with RT, which is a fractional recovery at the time of default of an otherwise identical Treasury bond. To do so, we need a $\mathrm{RT}$ rate comparable with $44 \% \mathrm{RFV}$. The two types of recovery assumptions are inequivalent for multiple maturities, but a $50 \%$ RT is roughly comparable with a $44 \%$ RFV for our relevant maturities. Relative to RFV, RT attaches slightly lower value to low coupon bonds trading below par, since they get a less favorable treatment in default. This is reflected in lower NPVs for the two shortest FT bonds step-up bonds with relatively low coupons. The effect is reversed for the FT 2008 bond and the DT step-up bonds with relatively high coupon rates, but overall the effect is small.

3. We introduced a non-default-related spread equal to the yield spread between a AAA corporate bond index and government bonds. We explore two different specifications of the non-default-related spread. First, we could ignore this issue and exclude the non-default-related spread. Second, Huang and Huang (2002) give quantitative guidelines for the non-default-related spread. In line with their findings we could, for our relevant rating classes, assume that it accounts for $80 \%$ of the spread for maturities up to 4 -years and $70 \%$ of the spread for maturities longer than 10-year and interpolate the fraction between 4 and 10 years. The conclusions are robust with respect to the assumption of non-default-related spreads, and at the same time these tests show that our results are insensitive to 
the choice of default-free benchmark.

4. In the base case we used the smoothed versions of the rating transition matrices published by the rating agencies. Using the original, unsmoothed matrices does not change the conclusions.

5. We had to make a simplifying assumption regarding the covariation of the Moody's and S\&P ratings. In Section 3.2, we assumed that the rating of one agency adapts to the rating of the other agency with probability $A=80 \%$ in each period. The conclusions are stable to extreme values of $A$. Looking at subperiods (not shown), as expected, the provision value is lower for independent ratings when the provision has not been triggered, and vice versa when the provision has already been triggered.

6. The issuer-specific default probabilities derived from the reference bonds are crucial for assessing the theoretical value of the step-up bonds, since small changes in the default probabilities translate into changes in the discounted principals that are relatively large compared to the size of the step-up cash flows. We only have a small number of reference bonds, and we need to assume a structure between the them. We address that problem in four ways. First of all, we note that the results are remarkably general across maturities whether the step-up bond (S) matures before, between or after the reference bonds $(\mathrm{R})$. The maturity sequences for the eleven DT bonds and the eight FT bonds are RRSRSRSSSRS and SSRRSRRR, respectively, and every single step-up bond has been significantly underpriced in most of the sample. Secondly, we observed that the NPV of the FT 2004 step-up bond converged to zero as we approached the penultimate coupon date, after which it is a standard fixed coupon bond. Importantly, this is not due to the entrance of a new FT reference bond in the calibration. This provides some evidence that the discount curves estimated from the FT reference bonds can in fact be used to value other FT issues, and towards the end of the sample we start to see the same convergence for other short step-up bonds. Thirdly, we rerun the computations with a flat risk-adjustment structure between reference bonds. Formally, as an alternative to (11), we apply

$$
\theta_{t}= \begin{cases}\alpha_{1} & \text { for } t=1, \ldots, T_{1} \\ \alpha_{2} & \text { for } t=T_{1}+1, \ldots\end{cases}
$$

The results are materially the same. Finally, we do a more conservative test by measuring each step-up bond against the cheapest of its two neighbors, where the neighbors are the two reference bonds maturing just before and after the relevant step-up bond. That is we calibrate the model with a constant $\theta$-structure to the neighbor with the highest implied default probabilities. We still get underpricing on sample average, although in many cases of significantly smaller degree. In summary, the results confirm that the selection of reference bonds and the practical implementation are indeed important. Overall the order of underpricing has, however, been higher than the uncertainty associated with these practical 


\begin{tabular}{lrrrrr}
\hline & $\begin{array}{r}\text { Amount } \\
\text { m EUR }\end{array}$ & Issued & $\begin{array}{r}\text { Theoretical } \\
\text { provision value }\end{array}$ & $\begin{array}{r}\text { Market } \\
\text { provision value }\end{array}$ & NPV \\
\hline Step-up bonds: & & & & & \\
DT 7.5\% May 29 2007 & 2,500 & May 25 2002 & 0.49 & -1.62 & 2.11 \\
DT 6.125\% Dec 4 2007 & 500 & Nov 25 2003 & 0.57 & -0.56 & 1.13 \\
DT 5.75\% Feb 12 2008 & 1,000 & Jan 29 2003 & 0.85 & -2.10 & 2.95 \\
DT 6.5\% Oct 7 2009 & 500 & Sep 27 2002 & 0.75 & -1.90 & 2.64 \\
FT 5.75\% Mar 14 2004 & 3,500 & Mar 7 2001 & 0.41 & -0.13 & 0.54 \\
FT 5\% Feb 26 2005 & 2,750 & Nov 8 2001 & 0.16 & -0.34 & 0.50 \\
FT 6.75\% Mar 14 2008 & 3,500 & Mar 7 2001 & 1.52 & -1.56 & 3.09 \\
Reference bonds: & & & & & \\
DT 5.25\% Sep 24 2004 & 500 & Sep 11 2002 & & & -0.47 \\
DT 5.5\% Sep 30 2005 & 500 & Sep 19 2002 & & & 0.48 \\
DT 5.25\% Jan 22 2007 & 500 & Jan 8 2002 & & & 0.84 \\
FT 6\% Sep 28 2007 & 1,000 & Jan 15 2003 & & & 1.76 \\
FT 7\% Dec 23 2009 & 2,000 & Dec 12 2002 & & & 1.16 \\
FT 7.25\% Jan 28 2013 & 3,000 & Jan 15 2003 & & & \\
\hline
\end{tabular}

Table 6: Pricing at issuance of step-up and reference bonds. The NPV is theoretical price, obtained from the calibrated model, minus market price.

considerations.

\subsection{Capital structure implications}

Our findings suggest the important implication that issuing corporate bonds with step-up provisions increased the cost of capital for the issuers. To address that, we need to investigate the pricing at issuance. For each bond issued within our sample - both step-up and fixed-coupon - we do that by calibrating the ratingbased model under the base case assumptions to all reference bonds issued prior to the issuance of that specific bond. Thus, new issues of both reference bonds and step-up bonds on their date of issuance have theoretical values which deviate from observed market values. We then look for underpricing by checking if these deviations are larger for step-up bonds.

Table 6 demonstrates that the step-up bonds were substantially underpriced at issuance. Remarkably, all step-up provisions have negative market values at issuance, so the underpricing is independent of how the rating transition probabilities are specified. To address the cost of capital consequences of issuing step-up bonds instead of fixed-coupon bonds, we need to compare with the pricing at issuance of the fixed-coupon reference bonds, which is also reported in Table 6 . For DT, the NPVs at issuance of step-up bonds are significantly higher than the NPVs of the reference bonds. For FT, the evidence is less clear. The FT 2013 fixed-coupon bond is more than two years longer than the longest reference bonds 
used to calculate its NPV, which is therefore very uncertain. The FT 2008 stepup bond was more underpriced at issuance than the comparable reference bonds maturing in 2007 and 2009. Apparently the underpricing at issuance of FT 2004 and 2005 was small. This can perhaps be explained by their short maturities which leave little time for the step-up provisions to take effect. In summary, we find evidence that issuing step-up bonds has increased the cost of capital for DT. For FT, there is some evidence that issuing the long-term, but not the short-term, step-up bonds increased the cost of capital.

Besides pricing, the financing decision is affected by other factors. In the classical capital structure theory, optimal debt is chosen as a trade off between tax benefits from debt on the one hand and the bankruptcy costs and agency costs from debt on the other. Bankruptcy costs and tax benefits both favor fixed-coupon bonds rather than step-up bonds, and actually an opposite couponstructure would be more efficient (like in income bonds, as mentioned by Miller (1977)). In the setting of Leland (1994), Manso, Strulovici, and Tchistyi (2003) argue that the bankruptcy costs of a step-up bond are higher than bankruptcy costs of a comparable fixed-coupon bond due to the so-called credit-cliff. Furthermore, the tax benefits are lower since part of the tax shield is postponed and the highest coupon payments are due in states of nature where the debtor may not be able to make (full) use of the tax shield. On the other hand, step-up bonds may reduce the agency costs of debt. The presence of the step-up clauses may reduce the incentives for asset substitution, since increasing the risk in favor of the equityholders may come at the cost of higher coupon payments to the bondholders depending on the distribution of the firm value and the reaction of the rating agencies. Agency costs are difficult to quantify, but in this case the reduction in agency costs is uncertain and likely to be small given the modest size of the step-ups, in particular for DT. Hence, it seems improbable that small, uncertain reductions in agency costs balances the three arguments against the issuance of step-up bonds: higher bankruptcy costs, lower tax benefits, and the underpricing we find.

\section{Conclusion}

We studied the relative pricing of step-up bonds and fixed-coupon bonds in the rating-based Markov chain model of Jarrow, Lando, and Turnbull (1997). Within this framework, we introduced a new calibration method, which overcomes the numerical problems with the calibration method of Jarrow, Lando, and Turnbull (1997) and the problems in interpreting risk premia inherent in the method of Kijima and Komoribayashi (1998). Additionally, we proposed simple ways of accounting for split ratings and rating outlook.

We find that step-up bonds issued by the two most active step-up bond issuers, Deutsche Telekom and France Telecom, have been underpriced through most 
of the sample. The conclusion is supported by model-independent yield curve observations, a calibrated rating-based model and a number of robustness checks. Because of maturity and coupon differences between the various issues, there were no direct static arbitrage opportunities. However, the rating-based model shows that the average underpricing was substantial - as much as $2 \%$ of face value on sample average in some cases. At the end of our sample, however, there is no clear evidence of underpricing.

Our findings cannot be attributed to traditional liquidity measures, but one might speculate that the complexity of the step-up provisions is what causes markets to discount these bonds. Complicated and non-standard assets may be priced with a discount irrespective of traditional liquidity measures. Stepup bonds are relatively simple assets but they require estimates of firm-specific rating probabilities, and in many cases they are unnecessarily complicated by path-dependence. Moreover, the stochastic cash flow is inconvenient for many investors focused on yields and yield spreads, and the precise language of the step-up provisions varies across issues resulting in a non-standardized market and making it difficult to compare different issues. This point has also been mentioned in several investment bank notes. ${ }^{24}$

These considerations are consistent with incomplete information stories in the asset pricing literature. Firstly, in a model with differential information across securities, Barry and Brown (1985) show that securities with more uncertainty to the return parameters can have higher expected returns in equilibrium. The return on a step-up bond is subject to rating transition risk, in addition to interest rate and default risk, and may therefore have higher estimation risk - the cash flow of a step-up bond depends explicitly on credit ratings, and firm-specific rating transitions probabilities can be hard to estimate. Secondly, in an incomplete

\footnotetext{
${ }^{24}$ E.g.: "The ensuing market confusion about pricing BT bonds with different coupon frequencies has once again highlighted the complexity of step-up bonds' valuation and called into question the usefulness of step-ups as an investor protection tool ... the task of differentiating bonds with various covenant packages has become increasingly complicated with virtually every new jumbo offering, because they all tend to devise variations on the step-up theme" Credit Suisse First Boston, Telecom Bonds with Coupon Step-Ups (May 30, 2001), and "Although coupon step-up bonds can provide some downside protection for investors, the benefits are partially undermined by the difficulties involved in accurately assessing the worth of step-ups. Since the telecom sector began issuing step-up bonds last summer, there has been a lot of confusion regarding the true worth of the step-up feature and debates regarding the benefits for bondholders. While most investors like the downside protection offered by these bonds, many analysts question the right way to value the step-ups" J.P. Morgan, European Telecoms Update (June 7, 2001), and "... investors and analysts have become aware that even though step-ups provide some downside protection in periods of uncertainty, they also create difficulties in correctly assessing relative value and comparisons between bonds. This is contrary to the idea of having a standardised bond language, necessary for a liquid market. Importantly, it adds an element of uncertainty to credit analysis, as investors have to rely increasingly on subjective decisions by rating agencies, causing some frustration" J.P. Morgan, European Telecoms Handbook (January 17, 2002).
} 
information model where investors only invest in securities about which they have enough information, Merton (1987) shows that the securities with limited participation have higher equilibrium expected returns. ${ }^{25}$ In the present case, some investors may choose to ignore step-up bonds due to information or setup costs. The fact that the underpricing becomes less significant towards the end of the sample also supports both of these explanations. As the step-up bonds approach maturity, the uncertainty of the cash flow, and therefore parameter uncertainty, decreases. Also, as time goes by, the knowledge about and participation in these securities may have increased.

Whatever the explanation for the underpricing, our results raise the question why firms issue step-up bonds in the first place. Apparently, the step-up provisions are trading below theoretical values, suggesting that they actually increase the cost of capital for the issuers. This is important since the step-up bonds account for almost a quarter of total liabilities for the two companies we studied.

\footnotetext{
${ }^{25}$ As one example, Merton gives: "... a bond trader who responds quickly to interest rate news by trading U.S. Treasury bonds, may not be willing to trade GNMA mortgage-backed bonds unless he has borne the set-up costs necessary to understand the effect on price of the prepayment feature of these bonds." Merton (1987, p. 489).
} 


\section{Appendix A: Rating actions}

\begin{tabular}{|c|c|c|c|c|}
\hline \multirow[b]{2}{*}{ Date } & \multicolumn{2}{|c|}{ DT } & \multicolumn{2}{|c|}{ FT } \\
\hline & Moody's & $\mathrm{S} \& \mathrm{P}$ & Moody's & $\mathrm{S} \& \mathrm{P}$ \\
\hline as of Jan 1, 2000 & Aa2 $(-2)$ & AA- $(0)$ & $\mathrm{Aa} 2(0)$ & AA $(-2)$ \\
\hline Apr 102000 & Aa2 $(-1)$ & & & \\
\hline Apr 282000 & & AA- $(-2)$ & & AA- $(0)$ \\
\hline May 302000 & & & Аа2 $(-2)$ & AA- $(-2)$ \\
\hline Jun 222000 & Aa2 $(-2)$ & & & \\
\hline Aug 232000 & & & & A $(0)$ \\
\hline Sep 182000 & & & A1 $(0)$ & \\
\hline Oct 52000 & A2 (0) & & & \\
\hline Oct 62000 & & A- $(0)$ & & \\
\hline Feb 122001 & A2 $(-1)$ & & & \\
\hline Feb 152001 & & & A3 (0) & \\
\hline Feb 162001 & & & & A- $(-1)$ \\
\hline Feb 262001 & & A- $(-2)$ & & \\
\hline Mar 202001 & A2 $(-2)$ & & & \\
\hline Jun 112001 & & A- $(-1)$ & & \\
\hline Jun 132001 & A3 $(-1)$ & & & \\
\hline Aug 132001 & & & A3 $(-1)$ & \\
\hline Sep 62001 & & & A3 $(-2)$ & A- $(-2)$ \\
\hline Sep 252001 & & & & $\mathrm{BBB}+(-1)$ \\
\hline Sep 262001 & & & Baa1 (0) & \\
\hline Feb 12002 & & & Baa1 (-1) & \\
\hline Feb 252002 & A3 $(-2)$ & & & \\
\hline Feb 262002 & & A- $(-2)$ & & \\
\hline Mar 272002 & & & Baa1 (-2) & \\
\hline Mar 282002 & Baa1 (0) & & & $\mathrm{BBB}+(-2)$ \\
\hline Apr 82002 & & $\mathrm{BBB}+(0)$ & & \\
\hline May 232002 & Baa1 (-1) & & & \\
\hline Jun 242002 & & & Вaа3 $(-1)$ & \\
\hline Jun 252002 & & & & $\operatorname{BBB}(-1)$ \\
\hline Jul 122002 & & & & BBB- $(0)$ \\
\hline Sep 132002 & & & Ваa3 (0) & \\
\hline Nov 182002 & Baal (-2) & & & \\
\hline Jan 102003 & Baa3 (0) & & & \\
\hline Mar 242003 & & & & BBB- $(+2)$ \\
\hline May 142003 & & & & BBB (0) \\
\hline Jun 242003 & Baa3 $(+1)$ & & & \\
\hline Sep 222003 & & & Baa3 $(+1)$ & \\
\hline
\end{tabular}

Table 7: Rating actions for DT and FT. The ratings are for senior unsecured in the period from January 1, 2000, to October 7, 2003. Rating outlook for Moody's/S\&P in parentheses: 0 (stable/stable), -1 (negative outlook/negative outlook), -2 (review for possible downgrade/negative watch), +1 (positive outlook/positive outlook), +2 (review for possible upgrade/positive watch). Source: Moody's and S\&P. 


\section{Appendix B: Path-dependent step-up provisions}

This appendix gives the details of the step-up provision value in the path-dependent case, (3), of Section 3.1.

Let the set of possible step-up amounts for a given step-up bond be denoted by $U$. Hence the expected value in (3) can be expressed as

$$
\begin{aligned}
& S^{(i, j)}\left(t, t_{m}\right)= f\left(u_{t_{-1}}, \eta_{t_{0}}^{M}, \eta_{t_{0}}^{S}\right) B\left(t, t_{1}\right) Q_{t}\left(\tau>t_{1}\right) \\
&+\sum_{k=1}^{K-1} \sum_{l=1}^{K-1} f\left(u_{t_{0}}, k, l\right) B\left(t, t_{2}\right) Q_{t}\left(\eta_{t_{1}}^{M}=k, \eta_{t_{1}}^{S}=l\right) \\
& \cdot Q\left(\tau>t_{2} \mid \eta_{t_{1}}^{M}=k, \eta_{t_{1}}^{S}=l\right) \\
&+\sum_{n=3}^{m} \sum_{k=1}^{K-1} \sum_{l=1}^{K-1} \sum_{u \in U} f(u, k, l) B\left(t, t_{n}\right) Q_{t}\left(u_{t_{n-2}}=u, \eta_{t_{n-1}}^{M}=k, \eta_{t_{n-1}}^{S}=l\right) \\
& \cdot Q\left(\tau>t_{n} \mid \eta_{t_{n-1}}^{M}=k, \eta_{t_{n-1}}^{S}=l\right)
\end{aligned}
$$

The terms involving the 3-dimensional Markov process are given by

$$
\begin{gathered}
Q_{t}\left(u_{t_{n-1}}=u, \eta_{t_{n}}^{M}=k, \eta_{t_{n}}^{S}=l\right)=\sum_{\bar{k}=1}^{K-1} \sum_{\bar{l}=1}^{K-1} \sum_{\bar{u} \in U} Q_{t}\left(u_{t_{n-2}}=\bar{u}, \eta_{t_{n-1}}^{M}=\bar{k}, \eta_{t_{n-1}}^{S}=\bar{l}\right) \\
Q Q\left(u_{t_{n-1}}=u, \eta_{t_{n}}^{M}=k, \eta_{t_{n}}^{S}=l \mid u_{t_{n-2}}=\bar{u}, \eta_{t_{n-1}}^{M}=\bar{k}, \eta_{t_{n-1}}^{S}=\bar{l}\right)
\end{gathered}
$$

where

$$
\begin{aligned}
& Q\left(u_{t_{n-1}}=u, \eta_{t_{n}}^{M}=k, \eta_{t_{n}}^{S}=l \mid u_{t_{n-2}}=\bar{u}, \eta_{t_{n-1}}^{M}=\bar{k}, \eta_{t_{n-1}}^{S}=\bar{l}\right) \\
& \quad= \begin{cases}Q\left(\eta_{t_{n}}^{M}=k, \eta_{t_{n}}^{S}=l \mid \eta_{t_{n-1}}^{M}=\bar{k}, \eta_{t_{n-1}}^{S}=\bar{l}\right) & \text { if } u=f(\bar{u}, \bar{k}, \bar{l}) \\
0 & \text { if } u \neq f(\bar{u}, \bar{k}, \bar{l})\end{cases}
\end{aligned}
$$

with the function $f$ defined by the specific provision. The four DT provisions are defined with $U=\{0,0.005\}$ and

$$
f(u, k, l)=u \mathbf{1}_{\{\max \{k, l\} \geq 8\}}+(0.005-u) \mathbf{1}_{\{\min \{k, l\} \geq 8\}}
$$

The provision of the FT 2005 bond is defined with $U=\{0,0.002,0.004, \ldots, 0.002(K-$ 9)\} and

$$
f(u, k, l)= \begin{cases}0.002[\min \{k, l\}-8]^{+} & \text {for } \min \{k, l\} \geq R \\ 0.002[\min \{R, \max \{k, l\}\}-8]^{+} & \text {for } \min \{k, l\}<R\end{cases}
$$

with $R=\frac{u}{0.002}+8$ being the rating level at which step-up was triggered at the previous coupon date. Note, if $k=l$ this simplifies to $f(u, k, l)=0.002[k-8]^{+}$. 


\section{Appendix C: Smoothing the transition matrix}

In this appendix we construct an idealized rating transition matrix $\tilde{P}$ by smoothing the empirical rating matrix $P$. This serves to remove unreliable humps in the empirical matrix, and another merit is strictly positive entries (in the first $K-1$ rows) which turn out to be convenient in applying the multiplicative adjustments proposed in Section 4.

It seems natural to require that the rating migration probability is nonincreasing in the size of the migration, measured by the number of rating notches. An exception, however, is the default event which may well be more likely than a downgrade to some of the lower non-default categories. Therefore, given an initial rating $i \in\{1, \ldots, K-1\}$, we will require that $\tilde{p}_{i j} \geq \tilde{p}_{i k}$ for $i \leq j \leq k \leq K-1$ and $\tilde{p}_{i j} \leq \tilde{p}_{i k}$ for $1 \leq j \leq k \leq i$. Additionally and more importantly, we will require that the default probability is higher the lower the initial credit quality, i.e. $\tilde{p}_{i K} \leq \tilde{p}_{j K}$ for $i \leq j \leq K$. It could also be argued, that the probability of being upgraded to a given rating $j$ should be non-decreasing in the initial credit quality, and vice versa below the diagonal. This property, however, is far from being fulfilled by the empirical matrices, in particular for lower rating categories, and imposing this restriction to $\tilde{P}$ would require severe adjustments of the empirical matrix. Hence, it will not be imposed in this approach, but it turns out that the extent of violations to this restriction is significantly reduced by the other restrictions imposed. We refer to Kijima (1998) for more on monotonicity of transition matrices.

In order to preserve some basic structure of the empirical matrix and to reflect the notion that rare events are estimated with the highest uncertainty the following restrictions are imposed on the smoothing method:

(i) Given any initial rating, the probability of unchanged rating is preserved, i.e. $\tilde{p}_{i i}=p_{i i}$ for $i=1, \ldots, K-1$.

(ii) Given any initial rating, the probability of a downgrade (including default) is preserved, i.e. $\sum_{j=i+1}^{K} \tilde{p}_{i j}=\sum_{j=i+1}^{K} p_{i j}$ for $i=1, \ldots, K-1$.

(iii) Given any initial rating, the probability of upgrade is preserved, i.e. $\sum_{j=1}^{i-1} \tilde{p}_{i j}=\sum_{j=1}^{i-1} p_{i j}$ for $i=2, \ldots, K-1$.

(iv) The sum of default probabilities is preserved, i.e. $\sum_{i=1}^{K} \tilde{p}_{i K}=\sum_{i=1}^{K} p_{i K}$.

The last property ensures that a portfolio consisting of a number of bonds evenly distributed among the $K-1$ rating categories has the same expected number of one-period defaults using $\tilde{P}$, as using $P$.

In general, all rows of the empirical rating matrix seem to follow a pattern of exponential decline away from the diagonal (excluding the default column). Hence, the entries of $\tilde{P}$ should be well approximated by an expression of the 


\begin{tabular}{llrllr}
\hline Moody's & historical & smoothed & S\&P & historical & smoothed \\
\hline Aaa & 0 & $1.8 \mathrm{E}-05$ & AAA & 0 & $2.3 \mathrm{E}-05$ \\
Aa1 & 0 & $3.3 \mathrm{E}-05$ & AA+ & 0 & $4.2 \mathrm{E}-05$ \\
Aa2 & 0 & 0.0001 & AA & 0 & 0.0001 \\
Aa3 & 0.0008 & 0.0001 & AA- & 0.0003 & 0.0001 \\
A1 & 0 & 0.0002 & A+ & 0.0006 & 0.0002 \\
A2 & 0.0002 & 0.0004 & A & 0.0004 & 0.0004 \\
A3 & 0 & 0.0007 & A- & 0.0005 & 0.0008 \\
Baa1 & 0.0008 & 0.0012 & BBB+ & 0.0019 & 0.0014 \\
Baa2 & 0.0007 & 0.0022 & BBB & 0.0031 & 0.0024 \\
Baa3 & 0.0046 & 0.0039 & BBB- & 0.0035 & 0.0043 \\
Ba1 & 0.0068 & 0.0071 & BB+ & 0.0052 & 0.0078 \\
Ba2 & 0.0072 & 0.0129 & BB & 0.0117 & 0.0139 \\
Ba3 & 0.0249 & 0.0234 & BB- & 0.0193 & 0.0248 \\
B1 & 0.0404 & 0.0424 & B+ & 0.0361 & 0.0444 \\
B2 & 0.0875 & 0.0770 & B & 0.1040 & 0.0793 \\
B3 & 0.1372 & 0.1397 & B- & 0.1351 & 0.1417 \\
Caa & 0.2960 & 0.2960 & CCC & 0.2826 & 0.2826 \\
\hline
\end{tabular}

Table 8: One-year default frequencies, historical and smoothed. Source: Moody's 1983-2001 (Hamilton, Cantor, and Ou (2002)) and S\&P 1981-2001 (Standard and Poor's (2002)).

type $\nu e^{-\mu k}$, where $k$ represents the horizontal distance to the diagonal in terms of rating notches. Similarly, the default column is represented by a vertically increasing exponential function. This structure ensures the desired monotonicities. $\tilde{P}$ is obtained by minimizing the quadratic deviations from the empirical matrix $P$ subject to the above mentioned restrictions, i.e. by fitting the parameters $(\mu, \nu)$ in the default column and in each row on either side of the diagonal.

Table 8 presents the default column of the historical Moody's and S\&P transition matrices (from Hamilton, Cantor, and $\mathrm{Ou}$ (2002) and Standard and Poor's (2002), respectively) as well as the smoothed versions. We do not show the entire matrices, but there is no sign of a systematic pattern of the modifications from the original to the smoothed matrix at the boundary between investment grade and speculative grade (between Baa3/BBB- and $\mathrm{Ba} 1 / \mathrm{BB}+$ ) or anywhere else, which would have indicated a problem with fitting the equidistant exponential functions. The equidistant exponential functions are admittedly subjective, but serves as a simple way of obtaining a more reliable rating matrix. 


\section{References}

Acharya, V., S. Das, and R. Sundaram (2002): "Pricing Credit Derivatives with Rating Transitions," Financial Analysts Journal, 58(3):28-44.

Aminud, Y. And H. Mendelson (1991): "Liquidity, Maturity and the Yields on U.S. Treasury Securities," Journal of Finance, 46(4):1411-1425.

Arvanitis, A., J. Gregory, and J.-P. Laurent (1999): "Building Models for Credit Spreads," Journal of Derivatives, 6(3):27-43.

Bangia, A., F. Diebold, A. Kronimus, C. Schagen, and T. SchuerMANN (2002): "Ratings migration and the business cycle, with applications to credit portfolio stress testing," Journal of Banking and Finance, 26(2-3):445474 .

BARry, C. B. And S. J. Brown (1985): "Differential Information and Security Market Equilibrium," Journal of Financial and Quantitative Analysis, 20(4):407-422.

Caouette, J. B., E. I. Altman, And P. Narayanan (1998): Managing Credit Risk - the Next Great Financial Challenge, John Wiley and Sons, New York.

Collin-Dufresne, P., R. S. Goldstein, And J. Martin (2001): "The Determinants of Credit Spread Changes," Journal of Finance, 56(6):2177-2207.

Das, S. And P. Tufano (1996): "Pricing Credit-Sensitive Debt Ehen Interest Rates, Credit Ratings and Credit Spreads are Stochastic," Journal of Financial Engineering, 5(2):161-198.

Duffee, G. (1998): "The Relation Between Treasury Yields and Corporate Bond Yield Spreads," Journal of Finance, 53(6):2225-2242.

- (1999): "Estimating the Price of Default Risk," Review of Financial Studies, 12(1):197-226.

Duffie, D. And K. Singleton (1999): "Modeling Term Structures of Defaultable Bonds," Review of Financial Studies, 12(4):687-720.

Elton, E., M. Gruber, D. Agrawal, and C. Mann (2001): "Explaining the Rate Spread on Corporate Bonds," Journal of Finance, 56(1):247-277.

GuHA, R. (2003): "Recovery of Face Value at Default: Empirical Evidence and Implications for Credit Risk Pricing," Working Paper, London Business School. 
Hamilton, D., R. Cantor, and S. Ou (2002): "Default \& Recovery Rates of Corporate Bond Issuers," Moody's Investors Service, New York, February 2002 .

Houweling, P., A. Mentink, And T. Vorst (2004a): "Comparing Possible Proxies of Corporate Bond Liquidity," Working Paper, Erasmus University Rotterdam, forthcoming in Journal of Banking and Finance.

(2004b): "Valuing Euro Rating-Triggered Step-Up Telecom Bonds," Journal of Derivatives, 11(3):63-80.

Huang, J.-Z. And M. Huang (2002): "How Much of the Corporate-Treasury Yield Spread is Due to Credit Risk?," Working Paper, Penn State and Stanford Universities.

Jarrow, R., D. Lando, And S. Turnbull (1997): "A Markov Model for the Term Structure of Credit Risk Spreads," Review of Financial Studies, 10(2):481-523.

Jarrow, R. And S. Turnbull (1995): "Pricing Options on Financial Securities Subject to Credit Risk," Journal of Finance, 50(1):53-85.

Jensen, M. C. And W. H. Meckling (1976): "Theory of the Firm: Managerial Behavior, Agency Costs and Ownership Structure," Journal of Financial Economics, 3(4):305-360.

Jordan, B. AND S. Jordan (1997): "Special Repo Rates: An Empirical Analysis," Journal of Finance, 52(5):2051-2072.

Keenan, S. C., J. S. Fons, And L. V. Carty (1998): "An Historical Analysis of Moody's Watchlist," Moody's Investors Service, New York, October 1998.

KiJimA, M. (1998): "Monotonicities in a Markov Chain Model for Valuing Corporate Bonds Subject to Credit Risk," Mathematical Finance, 8(3):229247.

Kijima, M. And K. Komoribayashi (1998): "A Markov Chain Model for Valuing Credit Risk Derivatives," Journal of Derivatives, 6(1):97-108.

LAndo, D. (1994): "Three Essays on Contingent Claims Pricing," PhD Dissertation. Cornell University.

(1998): "On Cox processes and Credit Risky Securities," Review of Derivatives Research, 2(2-3):99-120. 
(2004): Credit Risk Modeling: Theory and Applications, Princeton University Press.

Lando, D. And T. Skødeberg (2002): "Analyzing Rating Transitions and Rating Drift with Continuous Observations," Journal of Banking and Finance, 26(2-3):423-444.

Leland, H. E. (1994): "Corporate Debt Value, Bond Covenants, and Optimal Capital Structure," Journal of Finance, 49(4):157-196.

Longstaff, F. And E. Schwartz (1995): "A Simple Approach to Valuing Risky Fixed and Floating Rate Debt," Journal of Finance, 50(3):789-819.

Manso, G., B. Strulovici, And A. Tchistyi (2003): "PerformanceSensitive Debt and the Credit-Cliff Dynamic," Working Paper, Stanford University.

Merton, R. C. (1974): "On the Pricing of Corporate Debt: The Risk Structure of Interest Rates," Journal of Finance, 29(2):449-470.

(1987): "A Simple Model of Capital Market Equilibrium with Incomplete Information," Journal of Finance, 42(3):483-510.

Miller, M. (1977): "Debt and Taxes," Journal of Finance, 32(2):261-275.

Newman, Y. S. And M. A. Rierson (2003): "Illiquidity Spillovers: Theory and Evidence From European Telecom Bond Issuance," Working paper, Stanford University.

Ogden, J. And T. Moon (1993): "An Analysis of Reset Notes and RatingSensitive Notes," Journal of Financial Engineering, 2(2):175-194.

Sarig, O. And A. Warga (1989): "Bond Price Data and Bond Market Liquidity," Journal of Financial and Quantitative Analysis, 24(3):367-378.

Standard And Poor's (2002): "Ratings Performance 2001," Standard \& Poor's, New York, February 2002.

Svensson, L. (1994): "Estimating and Interpreting Forward Interest Rates: Sweden 1992-1994," NBER Working Paper 4871.

Warga, A. (1992): "Bond Returns, Liquidity, and Missing Data," Journal of Financial and Quantitative Analysis, 27(4):605-617. 
INSTITUT FOR FINANSIERINGs working papers siden 2000:

WP 2000-1 Bjarne Astrup Jensen and Carsten Sørensen: Paying for minimum interest rate guarantees: Who should compensate who?

WP 2000-2 Jan Jakobsen and Ole Sørensen: Decomposing and testing Long-run Returns with an application to initial public offerings in Denmark.

WP 2000-3 Jan Jakobsen and Torben Voetmann: Volatility-Adjusted Performance An Alternative Approach to Interpret Long-Run Returns.

WP 2000-4 Jan Jakobsen and Torben Voetmann: Post-Acquisition Performance in the Short and Long-Run Evidence from the Copenhagen Stock Exchange 1993-1997.

WP 2000-5 Ken L. Bechmann and Johannes Raaballe: A Regulation of Bids for Dual Class Shares. Implication: Two Shares - One Price.

WP 2000-6 Torben Voetmann: Changes in the Bid-Ask Componets Around Earnings Announcemtents: Evidence from the Copenhagen Stock Exchange.

WP 2000-7 Henrik Lando: The Optimal Standard of Proof in Criminal Law When Both Fairness and Deterrence Are Social Aims.

WP 2000-8 Jesper Rangvid and Carsten Sørensen: Convergence in the ERM and Declining Numbers of Common Stochastic Trends.

WP 2000-9 Claus Munk and Carsten Sørensen: Optimal Consumption and Investment Strategies with Stochastic Interest Rates.

WP 2000-10 Henrik Lando and Caspar Rose: On Specific Performance in Civil Law and Enforcement Costs.

WP 2000-11 Henrik Lando: Ny lov om jordforurening i økonomisk belysning.

WP 2001-1 Michael Møller, Claus Parum og Thomas Sørensen: Den ny pensionsafkastbeskatningslov.

WP 2001-2 Bjarne Astrup Jensen: Mean variance efficient portfolios by linear programming: A review of some portfolio selection criteria of Elton, Gruber and Padberg.

WP 2001-3 Caspar Rose: Impact of Investor Meetings/Presentations on Share 
Prices, Insider Trading and Securities Regulation.

WP 2001-4 Caspar Rose: Corporate Financial Performance and the Use of Takeover Defenses.

WP 2001-5 Shubhashis Gangopadhyay and Clas Wihlborg: The Impact of Bankruptcy Rules on Risky Project Choice and Skill Formation under Credit Rationing.

WP 2001-6 Claus Munk, Carsten Sørensen \& Tina Nygaard Vinther: Portfolio Choice under Inflation: Are Popular Recommendations Consistent with Rational Behaviour?

WP 2001-7 Ken L. Bechmann: Evidence on the Limits of Arbitrage: Short Sales, Price Pressure, and the Stock Price Response to Convertible Bond Calls.

WP 2001-8 Michael Møller \& Caspar Rose: Legal pre-emption rights as calloptions, redistribution and efficiency loss.

WP 2001-9 Peter Raahauge: Empirical Rationality in the Stock Market.

WP 2002-1 Bjarne Astrup Jensen: On valuation before and after tax in no arbitrage models: Tax neutrality in the discrete time model.

WP 2002-2 Ken L. Bechmann: Price and Volume Effects Associated with Changes in the Danish Blue-Chip Index - The KFX Index.

WP 2002-3 Steen Thomsen and Caspar Rose: Foundation ownership and financial performance. Do companies need owners?

WP 2002-4 Martin Richter and Carsten Sørensen: Stochastic Volatility and Seasonality in Commodity Futures and Options: The Case of Soybeans.

WP 2002-5 Caspar Rose: Aktiemarkedets reaktion på indførelsen af incitamentsprogrammer.

WP 2002-6 Caspar Rose: Impact of Takeover Defenses on Managerial Incentives.

WP 2002-7 ～Ken L. Bechmann og Peter Løchte Jørgensen: Optionsaflønning i danske børsnoterede selskaber.

WP 2002-8 Jesper Rangvid: Output and Expected Returns - a multicountry study.

WP 2002-9 Jonas Aziz Bhatti og Michael Møller: Pensionsafkastbeskatning og optimal porteføljesammensætning. 
WP 2003-1 Bjarne Florentsen, Michael Møller and Niels Chr. Nielsen: Reimbursement of VAT on written-off Receivables.

WP 2003-2: $\quad$ Ken L. Bechmann and Peter Løchte Jørgensen: The Value and Incentives of Option-based Compensation in Danish Listed Companies.

WP 2004-1 Ken L. Bechmann and Johannes Raaballe: The Difference Between Stock Splits and Stock Dividends - Evidence from Denmark.

WP 2004-2 Caspar Rose: Bestyrelsessammensætning og finansiel performance i danske børsnoterede virksomheder - Er Nørbyrapportens anbefalinger til gavn for aktionærerne?

WP 2004-3 Jens Lunde: Lack of balance in after-tax returns - lack of tenure neutrality. The Danish case.

WP 2004-4 Peter Raahauge: Upper Bounds on Numerical Approximation Errors.

WP 2004-5 Peter Raahauge: Higher-Order Finite Element Solutions of Option Prices.

WP 2004-6 Anders Holst \& Morten Nalholm: Modelling Callable Annuity Bonds with Interest-Only Optionality.

WP 2004-7 Bent Jesper Christensen \& Peter Raahauge: Latent Utility Shocks in a Structural Empirical Asset Pricing Model.

WP 2004-8 Carsten Sørensen and Anders Bjerre Trolle: Dynamic asset allocation and latent variables.

WP 2004-9 David Lando og Allan Mortensen: On the Pricing of Step-Up Bonds in the European Telecom Sector. 